\title{
OPTIMISATION OF BMP-2 DOSAGE FOR THE OSSEOINTEGRATION OF POROUS TITANIUM IMPLANTS IN AN OVINE MODEL
}

\author{
E.B. Hunziker ${ }^{1,2}$, J. Jovanovic ${ }^{1}$, A. Horner ${ }^{4}$, M. J. B. Keel ${ }^{1,3}$, K. Lippuner ${ }^{2,3}$ and N. Shintani ${ }^{2,3 *}$ \\ ${ }^{1}$ Department of Orthopaedic Surgery, Inselspital, University of Bern, Bern, Switzerland \\ ${ }^{2}$ Department of Osteoporosis, Inselspital, University of Bern, Bern, Switzerland \\ ${ }^{3}$ Department of Clinical Research, University of Bern, Bern, Switzerland \\ ${ }^{4}$ Smith \& Nephew, Research Centre, York, United Kingdom
}

\begin{abstract}
In clinical orthopaedics, total joint replacements and spinal fusions are routine undertakings. Many of the implicated patients suffer from osteoporosis, severe arthrosis or osteopaenia. In individuals thus afflicted, the bony bed lacks the mechanical stability that is a requisite for a firm anchorage of the implant and its functional competence. To promote the bony bondage of an implant it is necessary to induce neo-ossification by the introduction of an osteogenic agent, such as bone morphogenetic protein 2 (BMP-2). Since this growth factor is generally applied in a free form and at high dosages to maximise its osteogenicity, untoward side effects frequently ensue.

We hypothesise that the administration of BMP-2 using a suitable delivery vehicle, and its gradual, low dose release therefrom in a cell-mediated manner, would avert the triggering of undesired side effects and enhance its efficacy.

To test this postulate, implants of porous titanium were coated with a layer of calcium phosphate into which BMP-2 was biomimetically incorporated at dosages ranging from 0.8 to $500 \mu \mathrm{g} / \mathrm{g}$ of coating material (delivery system) prior to their surgical placement in the tibiae of adult sheep. The volume and the surface area of newly-formed bone were evaluated histomorphometrically after 3 and 6 weeks. The highest values were achieved using BMP-2 dosages of 20 to $100 \mu \mathrm{g} / \mathrm{g}$ of coating: The deposition of bone was confined to the immediate vicinity of the implant and was observed deep within the interstices of its meshwork, to the walls of which it bonded well. The findings of the study attest to the validity of our hypothesis.
\end{abstract}

Keywords: Porous titanium implants, locally-contained BMP-2, dosage optimisation, slow-release delivery system, osteoinduction, osseointegration.

\author{
*Address for correspondence: \\ Nahoko Shintani, PhD \\ Departments of Osteoporosis and Orthopaedic Surgery \\ Inselspital (DKF) \\ University of Bern \\ Murtenstrasse 35
}

3008 Bern, Switzerland

Telephone: +41316320937

Fax: +41316324999

Email: nahoko.shintani@dkf.unibe.ch

\section{Introduction}

There are many situations in clinical orthopaedics and dental implantology in which a tool wherewith to induce the neoformation of osseous tissue would be a very welcome alternative to the autologous transplantation of bone to facilitate or accelerate the healing of fractures and non-unions or the osseointegration of implants. One such potential tool is bone morphogenetic protein 2 (BMP-2). This osteogenic agent has been approved for clinical use in the context of spinal fusion, but not yet for other indications. Although clinical findings appertaining to the use of BMP-2 in spinal fusion are fairly impressive, the success of the procedure is often overshadowed by the manifestation of severe undesired side effects, which can seriously impair the health and the musculoskeletal functions of the treated patient (Faundez et al., 2016; James et al., 2016). These include ectopic bone formation, paralysis and neurological disturbances (Hofstetter et al., 2016; Vavken et al., 2015) [but not malignant pathologies (Cahill et al., 2015; Malham et al., 2015)].

BMP-2 is currently applied topically in a free form together with a collagenous matrix (Burkus et al., 2003). The recommended dosage is exceedingly high [e.g. $12 \mathrm{mg} / \mathrm{ACS}$ (absorbable collagen sponge), $7.5 \mathrm{~cm} \times 10 \mathrm{~cm} \times 0.4 \mathrm{~cm}, 0.322 \mathrm{~g}$; this corresponds to $37.3 \mathrm{mg}$ of BMP-2/g of ACS], and it is thus more than conceivable that therein lies the trigger for many of the untoward side effects (Benglis et al., 2008; Hofstetter et al., 2016). Many growth factors, including BMP-2, are known to act pleiomorphically. Whether one or another of the polarised effects is triggered depends critically upon the concentration of the agent. The induced response can, however, be readily reversed by a secondary adjustment of the dosage. BMP-2 acts osteoinductively at low (ng-to- $\mu \mathrm{g}$ ) concentrations (Herberg et al., 2014), and osteolytically at high ones in the mg range (Pobloth et al., 2015). Moreover, not only the concentration, but also the mode of application and the manner in which the agent is presented to the targeted population of progenitor cells can influence their response (anabolic or catabolic), as well as their differentiation pathway.

We hypothesise that if BMP-2 is presented to the targeted area in a form that is physiomimetic, which could be achieved by incorporating it into a bone-matrix-like material, then its effects would be confined to the said region. However, to avoid the triggering of undesirable side effects, the concentration at which the agent is liberated from its carrier must fall within the range that is maximally conducive to osteogenesis and minimally promotive of osteolysis. 


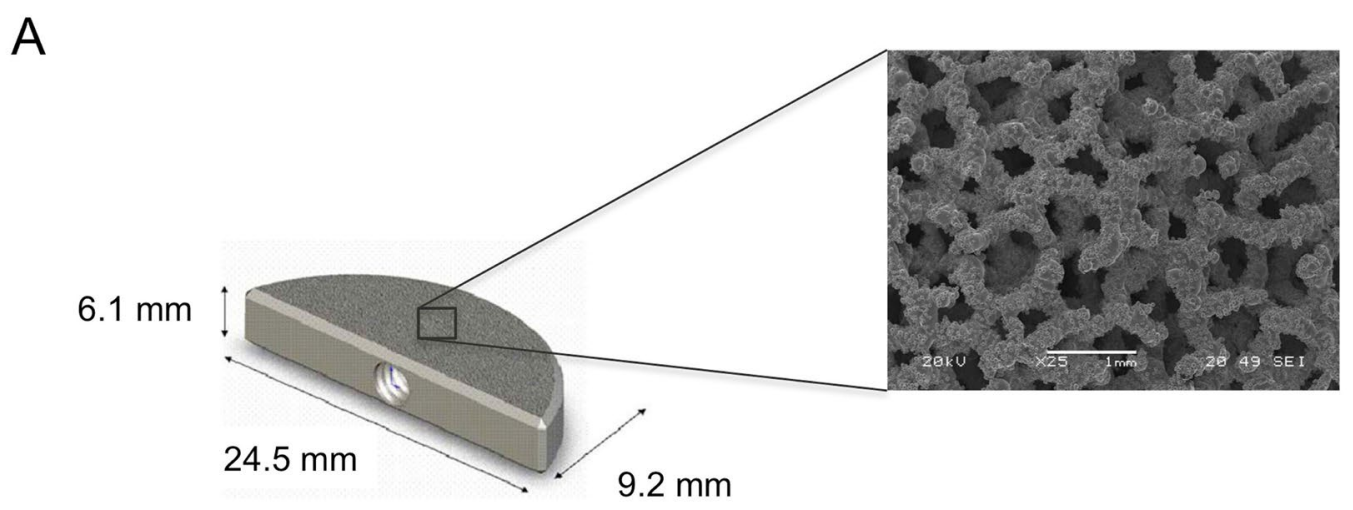

B

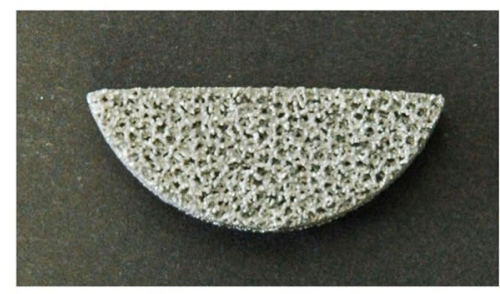

C

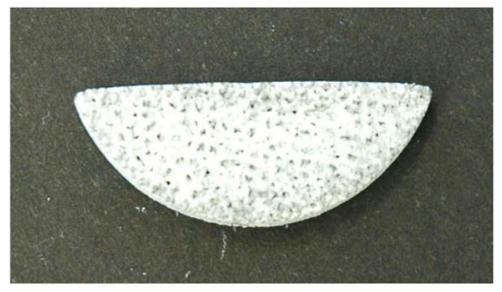

D

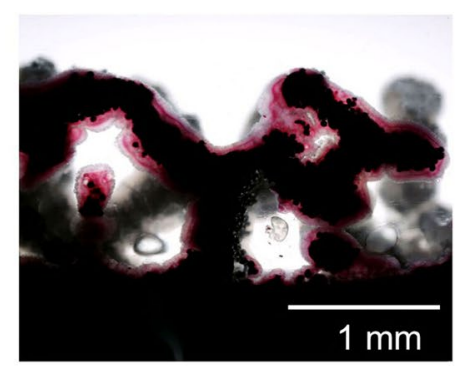

Fig. 1. Images of the experimental titanium implant. (A) Photograph of the implant at low magnification (left) and scanning electron micrograph of its porous surface (right). (B) Photograph of the implant without a coating. (C) Photograph of the implant after the biomimetic deposition of a layer of calcium phosphate. (D) Photograph of a vertical section through the porous mesh of the implant after the biomimetic deposition of a layer of calcium phosphate. The layer of calcium phosphate was stained with $2 \%$ Alizarin red.

The purpose of the present study was to elucidate the BMP-2-dosage range that is optimal for bone formation. To this end, the agent was incorporated at different concentrations into calcium-phosphate (bone-matrix-like) coatings (delivery system), which were simultaneously deposited upon experimental porous meshes of titanium. The agent is thereby released in a cell-controlled manner (Hagi et al., 2010; Liu et al., 2005a; Liu et al., 2005b). The prostheses were implanted within the tibiae of adult sheep. Bone formation and osseointegration were monitored histomorphometrically after 3 and 6 weeks. Optimal outcomes were achieved using concentrations of BMP-2 ( 20 to $100 \mu \mathrm{g} / \mathrm{g}$ of carrier) that lie very much closer to the intrinsic bony levels in mammals [1 to $3 \mathrm{ng} / \mathrm{g}$ of bone in bovine cows (Baylink et al., 1993; Wozney et al., 1988)] than do those that are currently applied in clinical practice (37300 $\mu \mathrm{g} / \mathrm{g}$ of carrier, see above).

\section{Materials and Methods}

\section{Porous titanium implant}

For the present study, we employed an experimental semi-circular implant (length: $24.5 \mathrm{~mm}$; width: $9.2 \mathrm{~mm}$; thickness: $6.1 \mathrm{~mm}$ ), which was designed and manufactured by Smith \& Nephew (London, UK). It is comprised of a solid core of titanium and an overlying porous mesh of the same metal (Fig. 1). The confinement of the porous mesh to the four faces, which are cut off from one another by the intervening solid core, ensures that the ingrowth of bone from each side of the implant can be independently quantified. The interconnectivity of the system of pores assures the continuous (unimpeded) ingrowth of blood vessels and osseous tissue.

\section{Biomimetic coating of the implants and the incorporation of BMP-2}

The biomimetic coating of the implants with a layer of octacalcium phosphate and the simultaneous incorporation of BMP-2 (Inductos, Medtronic AG, Münchenbuchsee, Switzerland) was performed as previously described (Liu et al., 2005a; Liu et al., 2004; Liu et al., 2006). In summary, a 1 to $3 \mu \mathrm{m}$-thick seeding layer of amorphous calcium phosphate was first deposited, then a thicker crystalline one (20 to $50 \mu \mathrm{m})$, into which BMP-2 was simultaneously incorporated. The entire coating procedure was conducted under sterile conditions. In a previous study, BMP-2 was established to be homogeneously distributed throughout the coating (Liu et al., 2003). To quantify the incorporated amounts of the agent (Table 1), the implants $(n=3$ for each dosage of BMP-2) were first soaked in $0.5 \mathrm{M}$ ethylenediaminetetraacetic acid (Sigma-Aldrich, St Louis, MO, USA) ( $\mathrm{pH} 8$ ) containing $0.1 \%$ bovine serum albumin (Sigma-Aldrich, St Louis, MO, USA) to dissolve the coating. The amount of BMP-2 in the solution was then determined using the human BMP-2 ELISA development kit (Peprotech, Rocky Hill, NJ, USA).

\section{BMP-2 concentrations}

In a preliminary study (unpublished data), we investigated the influence of two different, relatively high, concentrations of BMP-2: $2900 \mu \mathrm{g} / \mathrm{g}$ of coating and $6363 \mu \mathrm{g} / \mathrm{g}$ of coating, 
Table 1. BMP-2-concentration groups. Displayed are the targeted dosages/g of coating, the actual dosages/g of coating and the actual dosages/implant (mean values $\pm \mathrm{SEM} ; n=3$ in each case).

\begin{tabular}{|c|c|c|}
\hline Target dosage of BMP-2 & \multicolumn{2}{|c|}{ Actual dosage of BMP-2 } \\
\hline ( $\boldsymbol{\mu g} / \mathbf{g}$ of coating) & $(\boldsymbol{\mu g} / \mathbf{g}$ of coating) & ( $\boldsymbol{\mu g} / \mathbf{i m p l a n t})$ \\
\hline 0 (Control: no BMP-2; no coating) & 0 & 0 \\
\hline 0.8 & $0.7 \pm 0.2$ & 0.068 \\
\hline 4 & $4.7 \pm 0.5$ & 0.455 \\
\hline 20 & $18.6 \pm 3.5$ & 1.801 \\
\hline 100 & $85.2 \pm 8.2$ & 8.249 \\
\hline 500 & $478.4 \pm 14.5$ & 46.319 \\
\hline
\end{tabular}

which yielded total amounts per implant of $\sim 160 \mu \mathrm{g}$ and $\sim 350 \mu \mathrm{g}$, respectively. These dosages are approximately 10 -fold lower than those that are currently applied in clinical practice (Tannoury and An, 2014). At these two concentrations, the resorption of bone around the implants was massive after 3 weeks. Hence, their effects were not further pursued. The dosages of BMP-2 that were tested in the present study ranged from $0.8 \mu \mathrm{g}$ to $500 \mu \mathrm{g} / \mathrm{g}$ of coating; specifically, $0.8,4,20,100$ and $500 \mu \mathrm{g} / \mathrm{g}$ of coating (Table 1).

\section{Animal model}

For the present study, the animal model needed to be one with a limb size that was large enough to carry the implant and to furnish a sufficiency of trabecular bone to stably support it after insertion (sufficient primary stability). The proximal tibia of adult sheep satisfied these criteria.

The sheep were handled in accordance with the UK Animal Act (1986) and the associated guidelines (EU Directive 2010/EU for animal experiments).

\section{Surgery and anaesthesia}

A total of 18 quarantined adult stock sheep were used in the present study. Per animal, two implants were surgically inserted into the proximal tibia: one on the left side and one on the right. The treatment groups were allocated to each side according to a randomisation table.

To ascertain whether the volume of trabecular bone in the tibial plateau sufficed for implantation, the site was fluoroscopically screened prior to surgery.

General anaesthesia was induced by intramuscular injections of Ketamine (Narketan, Vetoquinol UK Ltd., Buckingham, UK: $100 \mathrm{mg} / \mathrm{mL}, 10 \mathrm{mg} / \mathrm{kg}$ of body weight) and Xylazine (Rompun, Bayer PLC, Newbury, UK: $20 \mathrm{mg}$ / $\mathrm{mL}, 0.1$ to $0.3 \mathrm{mg} / \mathrm{kg}$ of body weight), and was maintained with a mixture of isoflurane, oxygen and nitrous oxide. Buprenorphine (Buprecare, Animalcare Ltd, York, UK: $0.3 \mathrm{mg} / \mathrm{mL}, 0.01 \mathrm{mg} / \mathrm{kg}$ of body weight) was administered as an analgesic on the day of surgery, minimally $48 \mathrm{~h}$ thereafter, and subsequently as required. Infection was warded off prophylactically by an intramuscular injection of long-acting amoxicillin (Clamoxyl L.A, Zoetis UK Ltd., London, UK: $150 \mathrm{mg} / \mathrm{mL}, 15 \mathrm{mg} / \mathrm{kg}$ of body weight) at the time of surgery and for the two subsequent days. Using a standard surgical approach, an incision was made on the medial side of the proximal tibia and the soft tissue was resected to expose its medial surface. Defects were created $3 \mathrm{~mm}$ below and parallel to the medial tibial plateau. Two fixation-screw holes were then drilled into the bone and the base-plate was secured. Bony debris was removed by irrigation with saline solution. The implant was then press-fitted into the defect. After layer-by-layer closure of the wound, the procedure was repeated on the contralateral tibia. To ascertain whether the implants had been correctly inserted, the surgical sites were radiographed. During the recovery phase, the sheep were penned individually and observed until they had regained consciousness. The dermal sutures were removed either 10 to $14 \mathrm{~d}$ after surgery or as soon as healing had occurred (whichever came first).

\section{Histomorphometry}

At the end of the monitoring period, the sheep were killed by administering an overdose of pentobarbital. The hind limbs were harvested and the soft tissues removed. The proximal tibiae were severed from the tibial shafts approximately $5 \mathrm{~cm}$ distal to the tibial plateaus. The dissected proximal tibiae were chemically fixed in chilled $10 \%$ neutral formalin (Fisher Scientific, Loughborough, UK). The soft tissue was then removed from the front of each implant. The cutting band of an Exakt Macro Band saw (Exakt Technologies, Inc., Oklahoma City, OK, USA) was aligned with the anterior edge of the implant. The first sagittal cut was made at random within the first $5 \mathrm{~mm}$, according to a systematic random sampling protocol. The implant was then cut into four $4 \mathrm{~mm}$-thick slabs. The tissue slabs were immersed in $10 \%$ neutral-buffered formalin for a minimum of $7 \mathrm{~d}$ to complete the process of chemical fixation. All tissue slabs were dehydrated in ethanol, cleared in xylene and embedded in Technovit 7200VLC resin (Exakt Technologies, Inc., Oklahoma City, OK, USA). Sections were cut, ground down to a thickness of $\sim 30 \mu \mathrm{m}$ and then polished using the Exakt cutting and grinding system. Two sections per tissue slab were prepared. One section was stained with Alizarin Red (Sigma-Aldrich, St Louis, MO, USA) and the other with Sanderson's rapid bone stain (Dorn \& Hart Microedge, Inc., Loxley, AL, USA).

The sections were examined in a Nikon Eclipse E1000 light microscope (Nikon, Tokyo, Japan) and the two regions of interest identified, namely, the "mesh" space and the "peri-implant" space (Fig. 2A), which represent the reference areas for the histomorphometric analysis. Using a grid that conforms with established stereological principles (Gundersen et al., 1988), ten images per slide, eight in the mesh space and two in the peri-implant space, were captured at a final magnification of $10 \times$. With four slides 
A

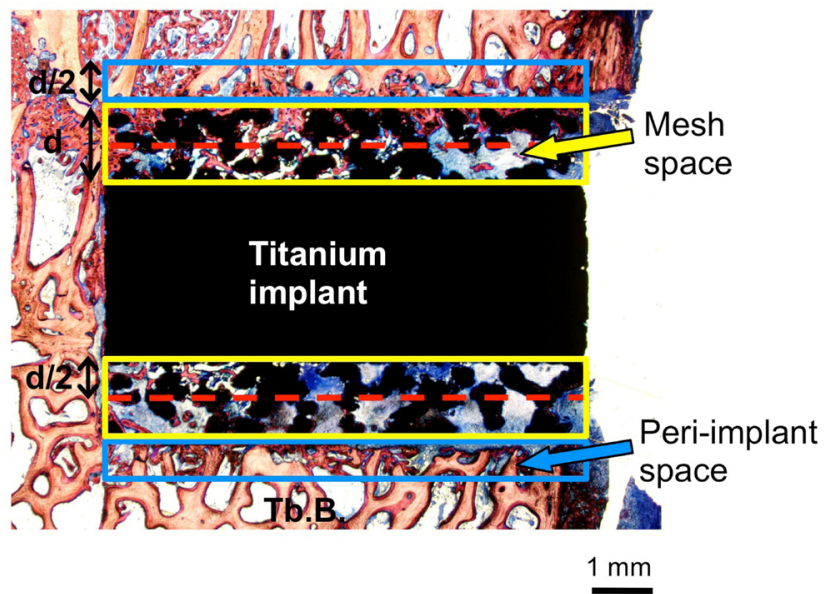

B

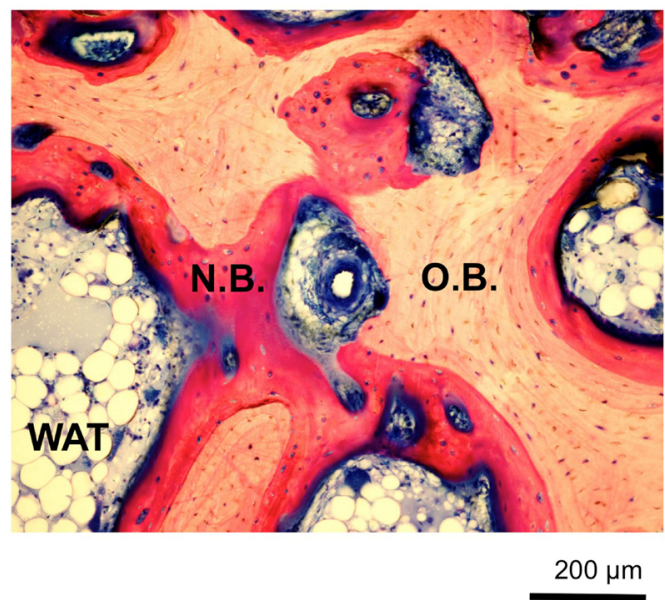

Fig. 2. (A) Low-magnification light micrograph of an implanted implant and (B) a higher-magnification view of the peri-implant space. (A) Histological image of a transverse section through an implant (black) after its insertion into the proximal tibial bone (Tb.B), illustrating the two reference spaces: the mesh space (boxed in yellow) and the peri-implant space (boxed in blue). Lengthwise, the peri-implant space had common borders with the implant; widthwise, it was defined to extend half of the distance (d/2) of the mesh space (d). (B) Histological image of a transverse section through the peri-implant space, illustrating the different tinctorial properties of pre-existing [(old) O. B.] and neo-formed bone (N.B.). WAT: white adipose tissue.

per implant, a total of 30 to 40 images were obtained per sample, which yielded $\sim 300$ to 500 point (or intersection) hits per parameter and per experimental group.

For the histomorphometric analysis, three different methods were implemented to estimate the targeted parameters: Cavalieri's method (Gundersen and Jensen, 1987) to estimate the volumes of the reference spaces, the point-counting method (Cruz-Orive and Weibel, 1990; Gundersen et al., 1988) to estimate the volume fraction $(\mathrm{Vv})$ of the estimators in the reference space (Vref), and the intersection method (Baddeley et al., 1986; Cruz-Orive and Weibel, 1990; Gundersen et al., 1988) to estimate the surface density $(\mathrm{Sv})$ of the estimators in the reference space. The estimated total volume (or total surface area) of each estimator was derived as the product of its volume fraction ( $\mathrm{Vv}$ ) [or surface density (Sv)] and the corresponding reference volume.

Assuming the reference volume (mesh or peri-implant space) to be the same for all implants, a mean value for six controls was determined. Within the mesh space, the porous volume was derived by subtracting the titanium mesh volume from the total volume of the mesh space. Within the peri-implant space, pre-existing and neo-formed bone were distinguished on the basis of their different tinctorial properties, the former having a light red and the latter a dark red hue (Fig. 2B).

Bone and coating volume fractions [ $\mathrm{Vv}$ (bone), $\mathrm{Vv}$ (coating)] in the mesh space were defined as volume fractions of the mean porous space. Three native (control) implants were used to estimate the pre-implantation coating volume (time point zero). Three additional implants per concentration group $(n=18)$ were used to calculate the mean coating weight $(\mathrm{mg})$. The implants were weighed with a high-precision balance before and after coating. The difference between the two weights gave the coating weight per implant. The mesh space was subdivided into inner and outer halves (Fig. 2A).
The intersection method was used to estimate the following interfacial areas in the porous space (Fig. 3): the bone-surface area (red line in Fig. 3), the bone-to-coating interfacial area (green line in Fig. 3), the titanium-tocoating interfacial area (yellow line in Fig. 3) and the titanium-to-bone interfacial area (blue line in Fig. 3). Using six control implants, the total surface area of the titanium mesh was determined. The mean value was used as the reference surface area of the mesh for all other implants. The total peri-implant space, as well as the surface areas of pre-existing and neo-formed bone, were also determined.

From the measured parameters, the following secondary estimators were computed for each time point: coating thickness $(\mu \mathrm{m})$, specific coating weight $\left(\mathrm{mg} / \mathrm{mm}^{3}\right.$ of coating), mass of residual coating ( $\mathrm{g}$ ), mass of degraded coating $(\mathrm{g})$, degraded coating volume $\left[\left(\mathrm{mm}^{3}\right)\right.$ at 3 weeks and 6 weeks], coating degradation rate $\left(\mathrm{mm}^{3} / \mathrm{d}\right)$, mean coating degradation rate $\left[\left(\mathrm{mm}^{3} / \mathrm{d}\right)\right.$ over 6 weeks $]$, uncoated surface area of titanium $\left(\mathrm{mm}^{2}\right)$, free surface area of titanium $\left[\left(\mathrm{mm}^{2}\right)\right.$ no bone or coating], bone-to-implant contact area $\left[\left(\mathrm{mm}^{2}\right) \mathrm{BIC}\right]$, absolute liberated amount of BMP-2 [( $\left.\mu \mathrm{g}\right)$ at each time point and over 6 weeks], absolute amount of BMP-2 in residual coating volume $(\mu \mathrm{g})$, mean BMP-2 release rate per day $[(\mu \mathrm{g} / \mathrm{d})$ at each time point and over 6 weeks], net efficacy of BMP-2 for bone volume $\left[\left(\mathrm{mm}^{3}\right.\right.$ of neo-formed bone $/ \mu \mathrm{g}$ of BMP-2) per time point and per reference space], net efficacy of BMP-2 for bone surface area $\left[\left(\mathrm{mm}^{2}\right.\right.$ of neo-formed bone/ $\mu \mathrm{g}$ of BMP-2) per time point and per reference space], net bone volume produced $\left(\mathrm{mm}^{3}\right)$ and trabecular thickness of neo-formed and preexisting bone ( $\mathrm{mm})$.

Previous studies have revealed BMP-2 to be homogeneously incorporated into the coating (Liu et al., 2004; Liu et al., 2003). Hence, the absolute amount of BMP-2 that is liberated is proportional to the amount of the coating that is degraded. Consequently, the absolute amount of liberated BMP-2 can be estimated from the 
Fig. 3. Schematic representation of the interfaces that were recognised in the mesh space of a titanium implant. The total surface area of neo-formed bone that was deposited along each of these interfaces was estimated histomorphometrically. Red line: bone-surface area; green line: bone-to-coating interfacial area; yellow line: titanium-to-coating interfacial area; blue line: titanium-to-bone interfacial area.

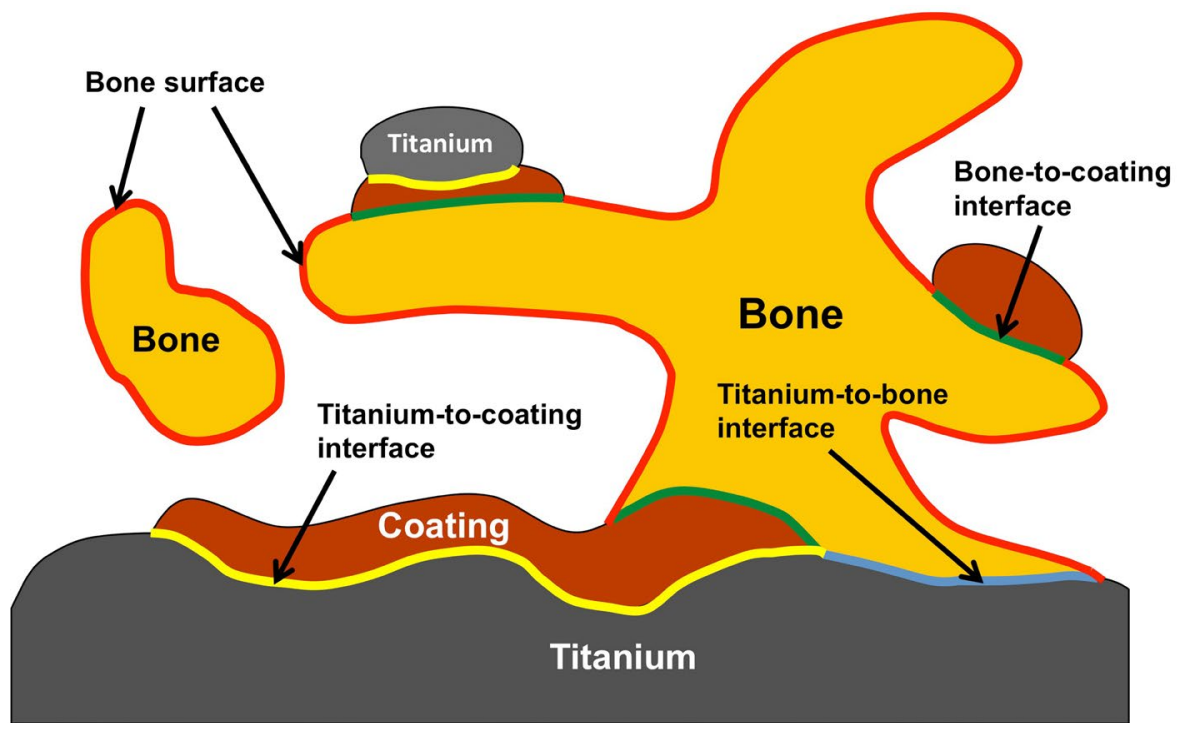

Table 2. Histomorphometric data appertaining to various stereological estimators in the control implants (no BMP-2; no coating) prior to their surgical placement (time point $=0$ ). $n=6$ in each case. CE: coefficient of error.

\begin{tabular}{|l|c|c|c|}
\hline & Mean & SEM & CE (\%) \\
\hline Reference volume of the mesh space $\left(\mathrm{mm}^{3}\right)$ & 378.5 & \pm 7.4 & 2.0 \\
\hline Reference volume of the peri-implant space $\left(\mathrm{mm}^{3}\right)$ & 194.2 & \pm 3.8 & 1.9 \\
\hline Volume of titanium in the mesh space $\left(\mathrm{mm}^{3}\right)$ & 127.6 & \pm 4.6 & 3.6 \\
\hline Volume of the porous space $\left(\mathrm{mm}^{3}\right)$ & 250.9 & \pm 6.1 & 2.4 \\
\hline Volume fraction of titanium $(\%)$ & 33.7 & \pm 1.0 & 2.9 \\
\hline Volume fraction of the porous space $(\%)$ & 66.3 & \pm 1.0 & 1.5 \\
\hline Surface area of titanium $\left(\mathrm{mm}^{2}\right)$ & 2093.2 & \pm 28.0 & 1.3 \\
\hline
\end{tabular}

degraded coating volume. According to the same premise, it is possible to estimate the amount of BMP-2 that is retained by the residual coating at the 3 - and 6 -week junctures.

Net BMP-2 efficacy was defined as the net volume of bone that was formed per microgram of liberated BMP-2 per time point. Net bone volume was calculated as the total bone volume minus the corresponding mean bone that was estimated in the implanted control. Gross BMP-2 efficacy was calculated as the absolute volume of bone that was deposited within the reference space per microgram of liberated BMP-2 per time point. All BMP-2 efficacies were calculated for both the mesh and the peri-implant spaces.

The bone-to-implant contact area (BIC), which is relevant for the implant-fixation strength and therefore for osseointegration, was defined as the surface area that is in direct contact with the titanium mesh (titanium-to-bone interfacial area) plus the indirect bone-to-titanium contact area [with an intervening layer of coating (Fig. 3)].

\section{Statistics}

All data are presented as mean values together with the standard error of the mean (SEM). Differences between the groups were analysed using the one-way ANOVA test. The level of significance was set at $p<0.05$. SPSS statistical software (SPSS Inc., Chicago, IL, USA, version 16 for Mac Os X) was used for the statistical calculations. Dunnett's two-sided post hoc test was implemented to compare the data in the control and the experimental groups.

\section{Results}

\section{Basic implant data}

To estimate the reference volumes, namely, the volume of the titanium mesh and that of the peri-implant space, as well as the surface area of the mesh, six control implants $(n=6)$ were analysed. The volume of the peri-implant space was estimated 3 and 6 weeks after surgical prosthetic placement. The volume and the surface area of the mesh were estimated prior to implantation (time point zero) and 3 weeks later. The implantation process per se had no influence on either the volume or the surface area of the mesh. The analyses revealed the mean volumes of the mesh and the peri-implant spaces to be $378.5 \pm 7.4 \mathrm{~mm}^{3}$ and $194.2 \pm 3.8 \mathrm{~mm}^{3}$, respectively (Table 2 ). The mean volume of the porous space in the mesh space was $250.9 \pm 6.1 \mathrm{~mm}^{3}$, with a volume fraction of $66.3 \pm 1.0 \%$. The intersection analysis of the mesh revealed its total surface area to be $2093.2 \pm 28.0 \mathrm{~mm}^{2}$ per implant (Table 2).

\section{Coating data at time point zero}

The analysis of the three unimplanted controls revealed the mean coating volume to be $98.2 \pm 6.2 \mathrm{~mm}^{3}$, with 
Table 3. Histomorphometric data appertaining to various coating parameters in the experimental implants prior to their surgical placement (time point $=0$ ). The estimations were made on three implants that were reserved specifically for these calculations.*: Average weight of 18 implants (including those that were placed in the animals). CE: coefficient of error.

\begin{tabular}{|l|c|c|c|}
\hline & Mean & SEM & CE (\%) \\
\hline Volume of coating $\left(\mathrm{mm}^{3}\right)$ & 98.2 & \pm 6.2 & 6.3 \\
\hline Coated surface area of titanium $\left(\mathrm{mm}^{2}\right)$ & 2031.2 & \pm 40.2 & 2.0 \\
\hline Uncoated surface area of titanium $\left(\mathrm{mm}^{2}\right)$ & 90.3 & \pm 14.3 & 15.9 \\
\hline Coated surface-area fraction of titanium $(\%)$ & 95.7 & \pm 0.7 & 0.7 \\
\hline Uncoated surface-area fraction of titanium $(\%)$ & 4.26 & \pm 0.7 & 15.8 \\
\hline Thickness of coating $(\mu \mathrm{m})$ & 48.3 & \pm 3.0 & 23.0 \\
\hline Weight of coating* $(\mathrm{mg})$ & 96.8 & \pm 1.4 & 1.5 \\
\hline Specific weight of coating $\left(\mathrm{mg} / \mathrm{mm}^{3}\right.$ of coating) & 0.99 & \pm 0.06 & 6.00 \\
\hline
\end{tabular}

$95.7 \pm 0.7 \%$ coverage of the total (inner and outer) porous titanium surface (Table 3). Hence, $2031.2 \pm 40.2 \mathrm{~mm}^{2}$ of the total surface area $\left(2093.2 \pm 28.0 \mathrm{~mm}^{2}\right)$ were completely covered with coating material, yielding a mean specific coating weight of $0.99 \pm 0.06 \mathrm{mg} / \mathrm{mm}^{3}$ of coating (Table 2 and Table 3 ). The mean thickness of the entire coating (amorphous and crystalline layers) was $48.3 \pm 3.0 \mu \mathrm{m}$. The coating weight that was measured for the 18 implants prior to their surgical placement ranged from $77.3 \mathrm{mg}$ to $105.1 \mathrm{mg}$, with an overall mean of $96.8 \pm 1.4 \mathrm{mg}$ [CE $($ coefficient of error $)=1.5 \%]($ Table 3$)$.

\section{Coating volumes 3 and 6 weeks after implant placement}

At time point zero (unimplanted control), the coating volume was $98.2 \pm 6.2 \mathrm{~mm}^{3}$ (Table 3 ). During the ensuing 3 weeks, the degree to which the coating was degraded tended to increase in parallel with the rise in BMP-2 concentration (Fig. 4). At the lowest concentration of BMP-2 $(0.8 \mu \mathrm{g} / \mathrm{g}$ of coating $)$, the residual coating volume at the 3 -week juncture was $65.6 \pm 1.8 \mathrm{~mm}^{3}$; the corresponding value at the second highest one $(100 \mu \mathrm{g} / \mathrm{g}$ of coating) was $39.7 \pm 11.3 \mathrm{~mm}^{3}$. Hence, the reduction in coating volume was $60.6 \%$ higher in the latter instance than in the former. At the highest concentration of BMP$2(500 \mu \mathrm{g} / \mathrm{g}$ of coating), the residual coating volume was $2.4 \pm 0.5 \mathrm{~mm}^{3}$, viz., $2.5 \%$ of the initial value. At the 6 - week juncture, the coating-degradation activity did not follow a dose-dependent trend; not, at least, below a BMP-2 concentration of $100 \mu \mathrm{g} / \mathrm{g}$ of coating (Fig. 4).

\section{BMP-2 concentrations}

The dosages of BMP-2 that were actually achieved $(\mu \mathrm{g} / \mathrm{g}$ of coating) corresponded well with the targeted ones (Table 1). The actual values were used to calculate the total amount of BMP-2 per implant (Table 1). In the preliminary study that was alluded to in the Materials and Methods section, the total amounts of BMP-2 per implant $(160 \mu \mathrm{g}$ and $350 \mu \mathrm{g})$, were 3 - to 7.5 -fold higher than the highest one in the present study $(46.3 \mu \mathrm{g}$, Table 1$)$.

\section{BMP-release kinetics}

Generally speaking, most of the coating-incorporated depot of BMP-2 was released during the first 3 weeks of implantation (Fig. 5A). However, at the lowest

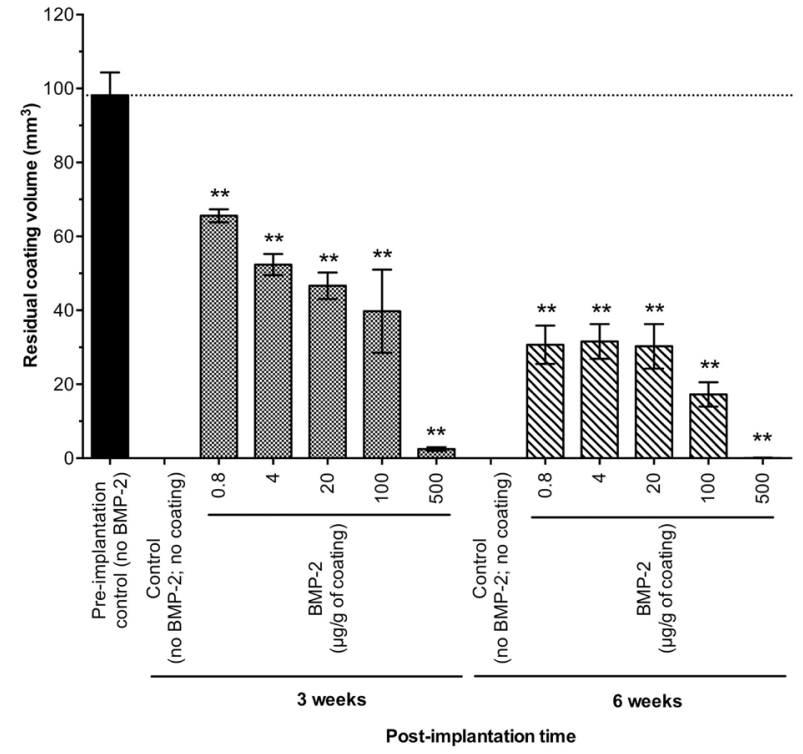

Fig. 4. Residual coating volumes 3 and 6 weeks after implant placement (mean values $\pm \mathrm{SEM} ; n=3$ in each case). The asterisks denote the level of statistical significance $(* * p<0.01)$ of comparisons with the preimplantation control.

concentration of BMP-2 $(0.8 \mu \mathrm{g} / \mathrm{g}$ of coating), this was not the case, the released amounts being $0.02 \pm 0.001 \mu \mathrm{g}$ and $0.05 \pm 0.004 \mu \mathrm{g}$ at the 3- and 6-week junctures, respectively. By contrast, at a BMP-2 concentration of $100 \mu \mathrm{g} / \mathrm{g}$ of coating, the corresponding values were $4.9 \pm 1.0 \mu \mathrm{g}$ and $6.9 \pm 0.3 \mu \mathrm{g}$, respectively. Hence, at concentrations of $0.8 \mu \mathrm{g} / \mathrm{g}$ of coating and $100 \mu \mathrm{g} / \mathrm{g}$ of coating, the amount of BMP-2 that was released at each of the two time points differed by $51.1 \%$ and $27.8 \%$, respectively. The increase in the (mean) absolute released amount of BMP-2 correlated very closely with the loaded dosage at each time point $\left(\rho_{3 \mathrm{w}}=0.99 ; \rho_{6 \mathrm{w}}=0.99\right)$.

The aforementioned observation was confirmed by calculating the BMP-2-release rates per day for the first 3 weeks and the second 3 weeks (Fig. 5B). The correlation coefficient for the first 3-week period was 0.99; that for the second was likewise 0.99 if the data appertaining to the highest concentration of BMP-2 (500 $\mu \mathrm{g} / \mathrm{g}$ of coating) were excluded; if they were included, it was 0.5 . 
A

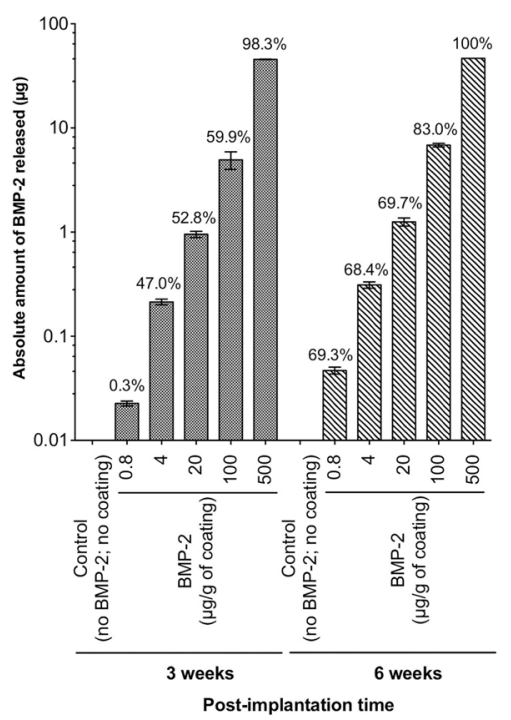

B

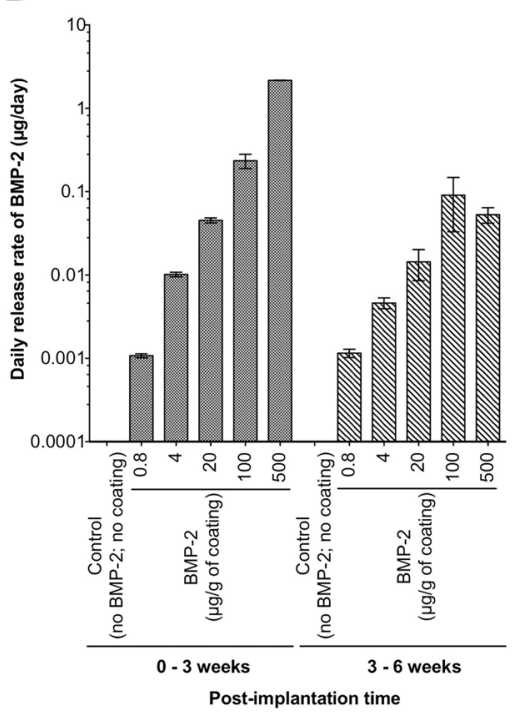

C

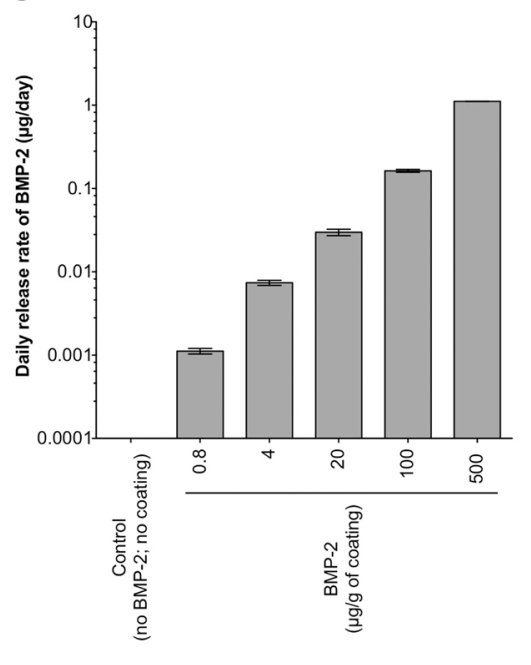

Fig. 5. BMP-2 release from the implants. (A) Absolute amounts of BMP-2 ( $\mu \mathrm{g})$ that were released 3 and 6 weeks after implant placement represented on a logarithmic scale (mean values \pm SEM; $n=3$ in each case). The percentage of BMP-2 that was released in each group is indicated above the corresponding column. (B) Daily release rates of BMP2,3 and 6 weeks after implant placement, represented on a decadal logarithmic scale (mean values \pm SEM; $n=3$ in each case). (C) Daily release rates of BMP-2, averaged over the 6-week monitoring period, represented on a decadal logarithmic scale ( $\pm \mathrm{SEM} ; n=6$ in each case).

A

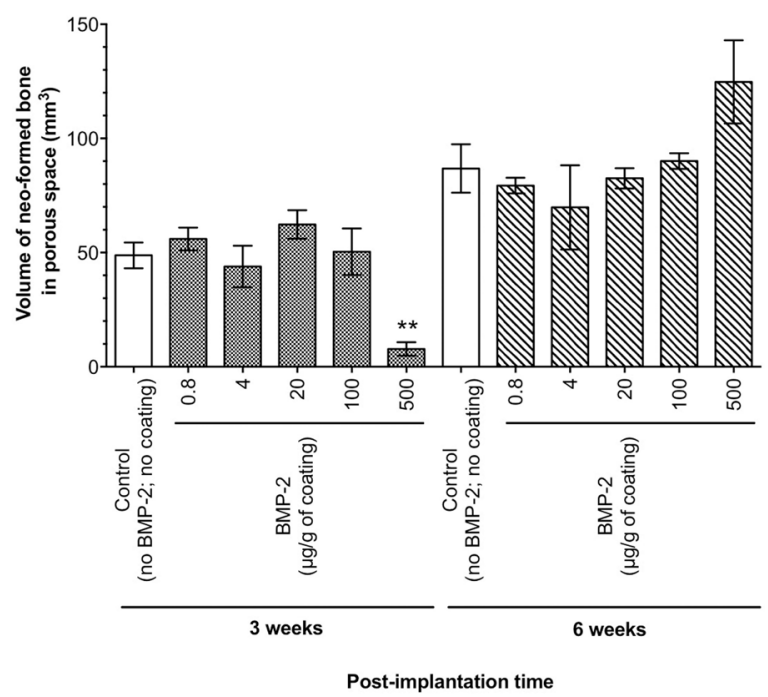

B

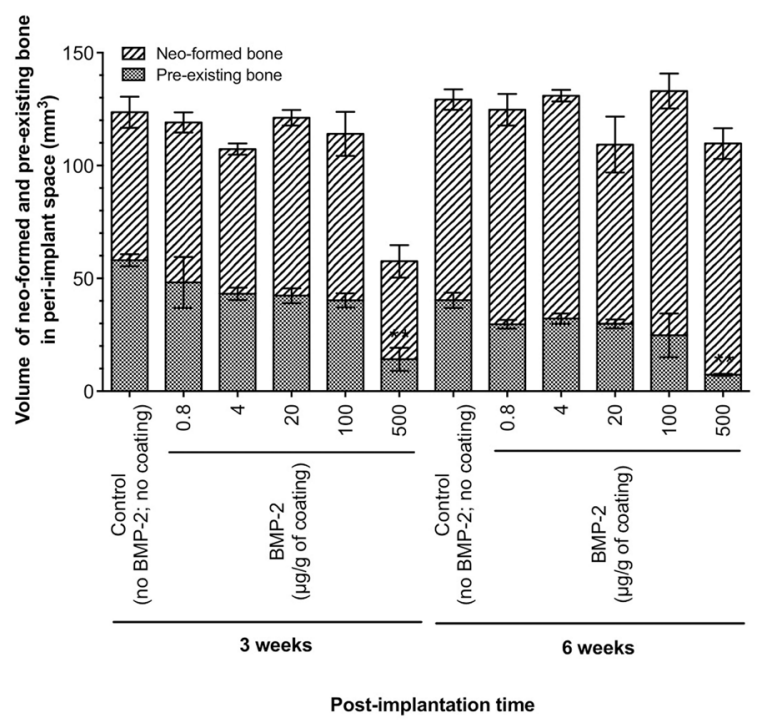

Fig. 6. Volumes of neo-formed bone. (A) Volumes of neo-formed bone in the porous space of the titanium mesh and (B) volumes of neo-formed and pre-existing bone in the peri-implant space 3 and 6 weeks after implant placement (mean $\pm \mathrm{SEM} ; n=3$ in each case). The asterisks denote the level of statistical significance $(* * p<0.01$ ) of comparisons with the control at each time point.

The mean BMP-2-release rate per day for the entire 6-week monitoring period was very closely and almost linearly related to the concentration of the agent $(\mu \mathrm{g} / \mathrm{g}$ of coating) $[\rho=0.99$ (Fig. 5C)].

\section{Bone volume in the porous space of the titanium mesh}

Somewhat surprisingly, at all BMP-2 concentrations except the highest one $(500 \mu \mathrm{g} / \mathrm{g}$ of coating), the volumes of neoformed bone in the porous space of the titanium mesh were comparable at both the 3-and the 6-week junctures and did not differ significantly from the control values (Fig. 6A). At the highest tested concentration, the bone volume was significantly lower at the 3 -week juncture $\left[7.9 \pm 2.9 \mathrm{~mm}^{3}\right.$; $p=0.006]$, and higher, albeit not significantly, at the 6week one $\left(124.7 \pm 18.2 \mathrm{~mm}^{3} ; p=0.144\right)$ (Fig. $\left.6 \mathbf{A}\right)$. The lower volume of osseous tissue at the 3-week juncture can be accounted for by a tip in the balance between bone formation and bone resorption activity towards the latter, which is a well-known response to high concentrations of 

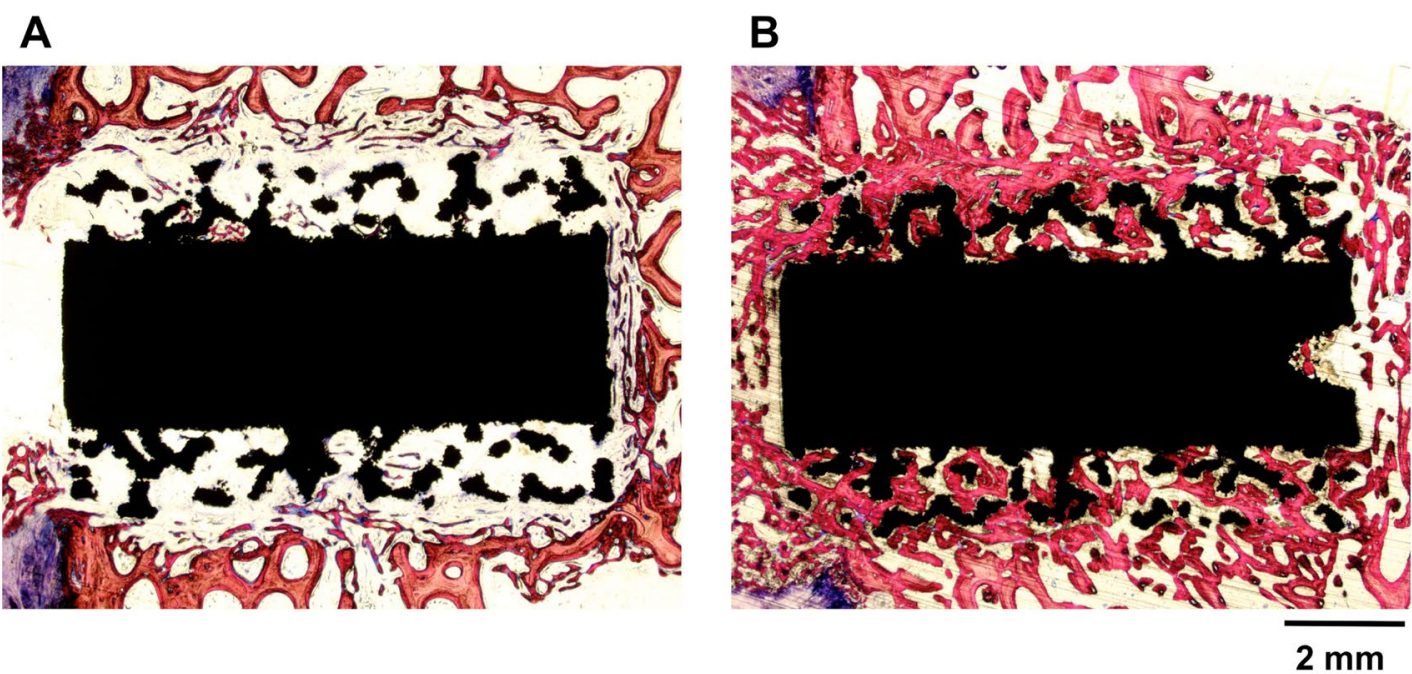

Fig. 7. Histological images of transverse sections through titanium implants upon which had been deposited a layer of calcium phosphate bearing a BMP-2 concentration of $500 \mu \mathrm{g} / \mathrm{g}$ of coating (A) 3 and (B) 6 weeks after their insertion into the proximal tibial bone. (A) At the 3-week juncture, the resorption of bone outweighed its formation in both the mesh and the peri-implant spaces, as evidenced by the lack of staining for osseous tissue. (B) By the end of the 6 th week, the balance between bone resorption and bone formation had been tipped in favour of the latter process.

BMP-2 (Herberg et al., 2014). By the 6th week, the local concentration of BMP-2 had dropped to a level at which the balance between bone formation and bone resorption activity favoured the former process. These explanations are borne out by the images in Fig. 7. The absence of staining in the porous as well as in the peri-implant space at the 3-week juncture (Fig. 7A) attests that not only neoformed but also pre-existing bone had been resorbed. At the 6-week juncture, staining for bone is observed in both spaces (Fig. 7B).

\section{Neo-formed and pre-existing bone volumes in the peri-implant space}

In the peri-implant space, the pattern of bone formation and resorption was similar to that in the porous one (Fig. $6 \mathbf{B})$. The volumes of total and neo-formed bone were comparable to each other and to the control values at both the 3 - and the 6-week junctures at all concentrations of BMP-2 except the highest one $(500 \mu \mathrm{g} / \mathrm{g}$ of coating). However, the volume of pre-existing bone at the 3-week juncture tended to decrease with an increase in BMP-2 concentration, although the difference attained statistical significance only at the highest dosage $(p=0.001)$. At the 6-week juncture, no such trend was observed, except at the highest BMP-2 concentration, and the difference was statistically significant $(p=0.001)$ (Fig. 6B).

\section{Bone surface area in the porous space of the titanium mesh}

At the 3-week juncture, the surface area of neo-formed bone in the porous space of the titanium mesh tended to be higher than that in the control at all BMP-2 concentrations except the highest one $(500 \mu \mathrm{g} / \mathrm{g}$ of coating) (Fig. 8A). However, the increase attained statistical significance only at dosages of $0.8 \mu \mathrm{g} / \mathrm{g}$ of coating $(p=0.02)$ and $20 \mu \mathrm{g} / \mathrm{g}$ of coating $(p=0.02)$. At the highest concentration of BMP-2, the surface area of neo-formed bone tended to be lower than that in the control, but the difference was not statistically significant $(p=0.1)$. At the 6-week juncture, the surface area of neo-formed bone was tendentially higher than that in the control group at all BMP-2 concentrations (significantly so except at $4 \mu \mathrm{g} / \mathrm{g}$ of coating) (Fig. 8A).

\section{Neo-formed and pre-existing bone surface areas in the peri-implant space}

In the peri-implant space, the surface area of neo-formed bone at the 3-week juncture was significantly higher (than that in the control) at the three lower BMP-2 concentrations $(0.8 \mu \mathrm{g} / \mathrm{g}$ of coating, $p=0.001 ; 4 \mu \mathrm{g} / \mathrm{g}$ of coating, $p=0.002$; $20 \mu \mathrm{g} / \mathrm{g}$ of coating, $p=0.009)$, but not at the two higher ones $(100 \mu \mathrm{g} / \mathrm{g}$ of coating, $p=0.12 ; 500 \mu \mathrm{g} / \mathrm{g}$ of coating, $p=0.48$ ) (Fig. 8B). At the 6-week juncture, the surface area of neo-formed bone did not differ significantly from that in the control group at any of the BMP-2 concentrations. At the 3-week juncture, the surface area of pre-existing bone did not differ significantly from that in the control group at any of the BMP-2 concentrations except the highest one, in which case it was lower $(p=0.02)$. At the 6 -week juncture, the surface area of pre-existing bone was significantly lower than that in the control group at the two highest BMP-2 concentrations $(100 \mu \mathrm{g} / \mathrm{g}$ of coating, $p=0.03 ; 500 \mu \mathrm{g} / \mathrm{g}$ of coating, $p=0.001)$.

\section{Trabecular thickness of bone in the porous space of the titanium mesh}

At the 3-week juncture, the trabeculae of neo-formed bone in the porous space of the titanium mesh were significantly thinner than those in the control and of comparable values at all BMP-2 concentrations (Fig. 9A). At the 6-week juncture, the trabeculae of neo-formed bone were likewise significantly thinner than those in the control, and likewise of comparable values, at all BMP-2 concentrations except the highest one, in which case no difference was observed $(p=0.110)$. 

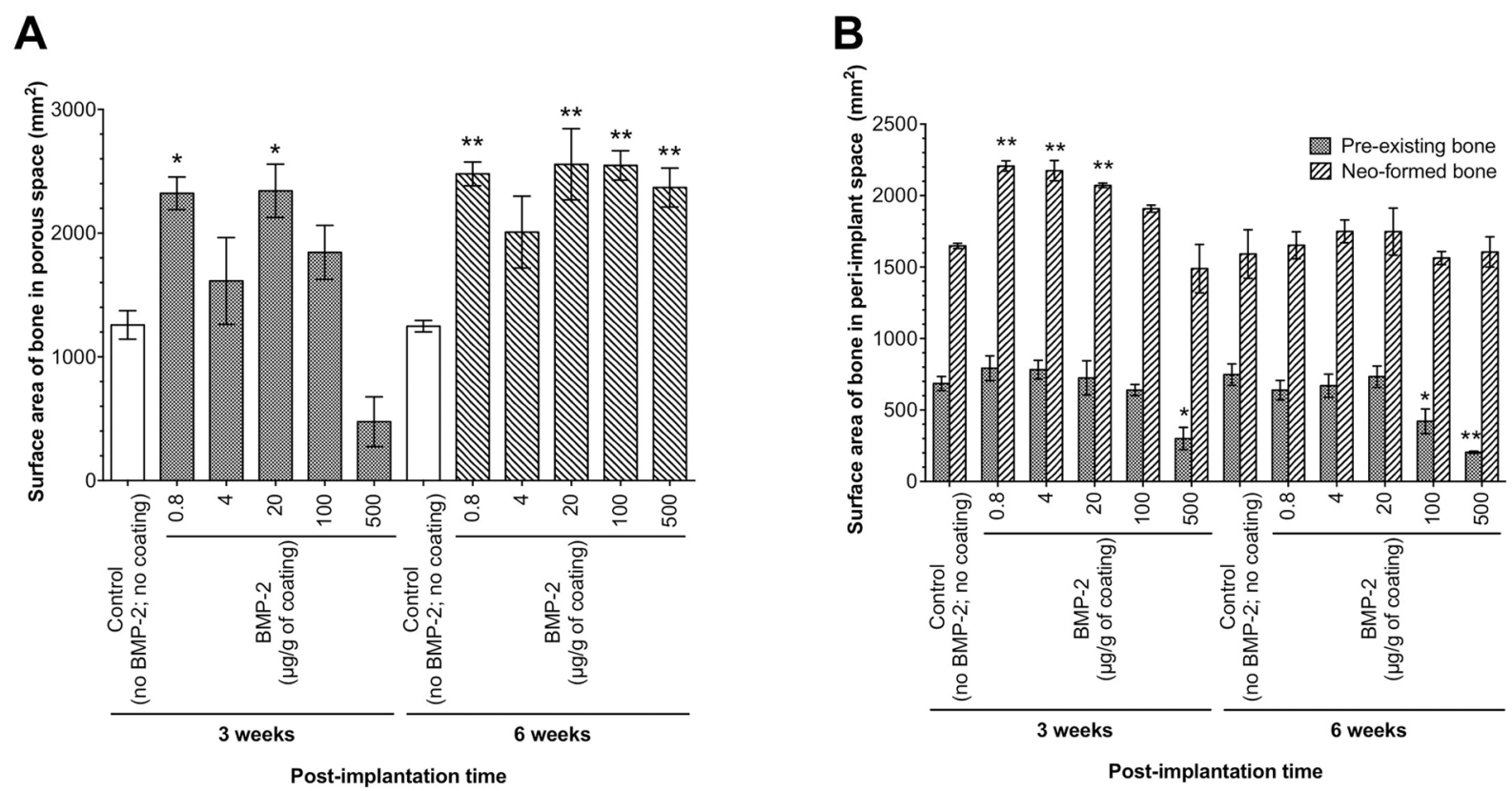

Fig. 8. Bone surface area. (A) Surface areas of bone in the porous space of the titanium mesh 3 and 6 weeks after implant placement (mean values $\pm \mathrm{SEM} ; n=3$ in each case). The asterisks denote the levels of statistical significance $(* p<0.05 ; * *<0.01)$ of comparisons with the control at each time point. (B) Surface areas of neo-formed and pre-existing bone in the peri-implant space 3 and 6 weeks after implant placement (mean values \pm SEM; $n=3$ in each case). The asterisks denote the levels of statistical significance $(* p<0.05 ; * * p<0.01)$ of comparisons with the control at each time point.

A

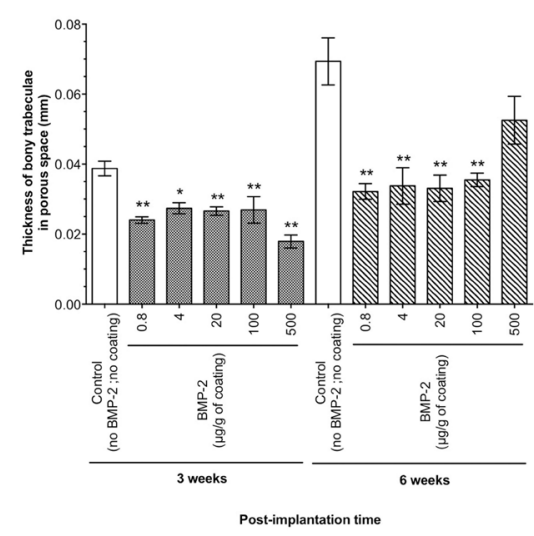

B

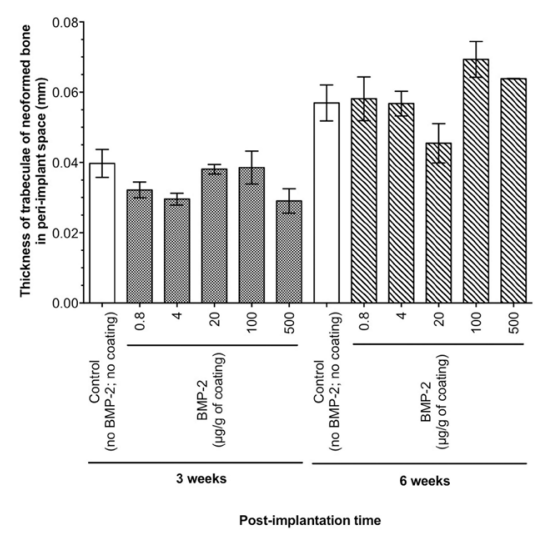

C

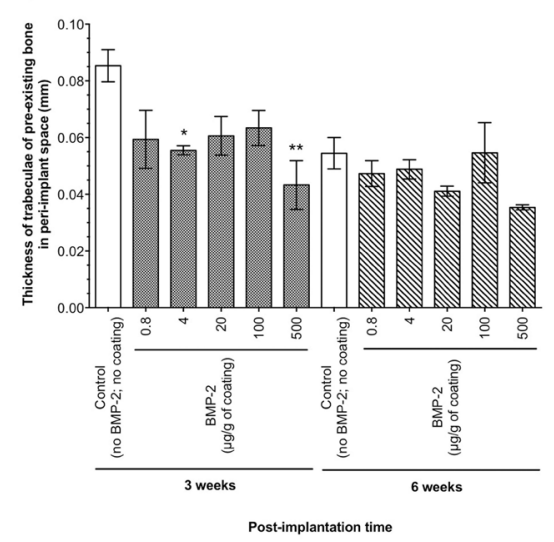

Fig. 9. Thickness of bone. (A) Thickness of the bony trabeculae in the porous space of the titanium mesh, (B) thickness of the trabeculae of neo-formed bone in the peri-implant space and $(\mathbf{C})$ thickness of the trabeculae of preexisting bone in the peri-implant space 3 and 6 weeks after implant placement (mean $\pm \mathrm{SEM} ; n=3$ in each case). The asterisks denote the level of statistical significance $(* * p<0.01)$ of comparisons with the control at each time point.

Trabecular thickness of neo-formed and pre-existing bone in the peri-implant space

In the peri-implant space, the thickness of the new bony trabeculae did not differ significantly from that in the control at any of the BMP-2 concentrations, either at the 3-week or at the 6-week juncture (Fig. 9B). The trabeculae of pre-existing bone tended to be thinner than those in the control at the 3-week juncture, but the difference attained statistical significance only at BMP-2 concentrations of $4 \mu \mathrm{g} / \mathrm{g}$ of coating $(p=0.04)$ and $500 \mu \mathrm{g} / \mathrm{g}$ of coating $(p=0.005)$ (Fig. 9C). By the end of the 6th week, the mean thickness of the pre-existing bony trabeculae did not differ significantly from that in the control at any of the tested BMP-2 concentrations.

\section{Bone-to-implant contact area (BIC)}

The total bone-to-implant contact area [direct bone-toimplant contact area plus indirect bone-to-implant contact area (with an intervening layer of coating)] at each of the two time points ( 3 and 6 weeks) increased relative to that in the controls $\left(234.8 \pm 18.5 \mathrm{~mm}^{2}\right.$ and $313.3 \pm 47.6 \mathrm{~mm}^{2}$, respectively) at all BMP-2 concentrations except the highest one (500 $\mu \mathrm{g} / \mathrm{g}$ of coating) (Fig. 10 and Table 4), and the dose-dependent patterns were comparable at each juncture. At the 3-week juncture, the highest value was attained at a BMP- 2 concentration of $0.8 \mu \mathrm{g} / \mathrm{g}$ of coating (922.6 $\left.\pm 55.2 \mathrm{~mm}^{2}, p<0.01\right)$, viz., at the lowest dosage, followed by that at $20 \mu \mathrm{g} / \mathrm{g}$ of coating $\left(795.1 \pm 92.2 \mathrm{~mm}^{2}\right.$, $p<0.01$ ) (Fig. 10). The increases relative to the control 
Table 4. Percentage of the total surface area of the titanium implants that were covered either directly or indirectly (intervening layer of coating) with bone (BIC), 3 and 6 weeks after implant placement. Values presented as mean values $\pm \mathrm{SEM} ; n=3$ in each case.

\begin{tabular}{|c|c|c|}
\hline \multirow{2}{*}{$\begin{array}{c}\text { BMP-2-concentration group } \\
\text { ( } \boldsymbol{\mu g / g} \text { of coating) }\end{array}$} & \multicolumn{2}{|c|}{ BIC (\%) } \\
\cline { 2 - 3 } 0 (control) & 3 weeks & 6 weeks \\
\hline 0.8 & $11.2 \pm 0.9$ & $15.0 \pm 2.3$ \\
\hline 4 & $44.1 \pm 2.6$ & $62.6 \pm 3.5$ \\
\hline 20 & $21.6 \pm 4.0$ & $45.0 \pm 9.3$ \\
\hline 100 & $38.0 \pm 4.4$ & $58.8 \pm 6.3$ \\
\hline 500 & $21.1 \pm 6.1$ & $45.0 \pm 3.7$ \\
\hline & $0.8 \pm 0.4$ & $14.1 \pm 1.8$ \\
\hline
\end{tabular}

value were thus $44.1 \pm 2.6 \%$ and $38.0 \pm 4.4 \%$, respectively (Table 4).

At the 6-week juncture, the direct BIC constituted a higher proportion of the total BIC than it did at 3 weeks (Fig. 10) - a finding that reflects the lower residual volumes of the coatings, which had undergone further degradation during the intervening period. This process of coating degradation had advanced to the greatest degree at the highest BMP-2 concentration (500 $\mu \mathrm{g} / \mathrm{g}$ of coating). At this dosage, the residual coating volumes at the 3- and 6week junctures were $2.4 \pm 0.5 \mathrm{~mm}^{3}$ and $0.08 \pm 0.08 \mathrm{~mm}^{3}$, respectively (Fig. 4); the corresponding indirect BICs were $4.1 \pm 3.1 \mathrm{~mm}^{2}$ and $1.8 \pm 1.8 \mathrm{~mm}^{2}$, respectively (Fig. 10).

\section{Net BMP-2 efficacy as appertaining to the bone} surface area in the porous space of the titanium mesh With respect to bone surface area, an inverse relationship between BMP-2 efficacy and BMP-2 concentration was clearly identifiable (Fig. 11, Table 5). A reduction in bone surface area was observed only at the highest BMP-2 concentration ( $500 \mu \mathrm{g} / \mathrm{g}$ of coating) at the 3 -week juncture $\left(-17.2 \pm 4.5 \mathrm{~mm}^{2} / \mathrm{d}\right.$ ) (Table 5$)$. At the lowest BMP-2 concentration $(0.8 \mu \mathrm{g} / \mathrm{g}$ of coating $)$, the BMP2 efficacy at the 3-week juncture was 31.8-fold higher than that at the 5 -fold higher dosage $(4 \mu \mathrm{g} / \mathrm{g}$ of coating) $\left(46639.5 \pm 3823.2 \mathrm{~mm}^{2} / \mathrm{d} v s .1468 .6 \pm 1639.3 \mathrm{~mm}^{2} / \mathrm{d}\right)$. At the 6-week juncture, the BMP-2 efficacy was still 10.2fold higher at the lowest dosage of the agent $(0.8 \mu \mathrm{g} / \mathrm{g}$ of coating) than at the 5 -fold higher one ( $4 \mu \mathrm{g} / \mathrm{g}$ of coating) $\left(26433.5 \pm 2154.3 \mathrm{~mm}^{2} / \mathrm{d}\right.$ vs. $\left.2582.0 \pm 1034.3 \mathrm{~mm}^{2} / \mathrm{d}\right)$. At the three yet higher BMP-2 concentrations (20, 100 and $500 \mu \mathrm{g} / \mathrm{g}$ of coating), the two 5-fold-step increases in dosage (viz., between 20 and $100 \mu \mathrm{g} / \mathrm{g}$ of coating, and between 100 and $500 \mu \mathrm{g} / \mathrm{g}$ of coating), yielded BMP-2 efficacy increases ranging from 1.25-fold to 10.1-fold at both time points. The average increase in BMP-2-efficacy over the 6-week monitoring period was 9.5 -fold. If the values at the lowest dosage of BMP-2 were excluded, then the average increase in BMP-2 efficacy per 5-fold-step increase in BMP-2 concentration for the 6-week period was 5.7-fold, viz., the parameter was almost halved.

Bone volume in the deeper half of the porous space of the titanium mesh

In the deeper half of the porous space of the titanium mesh, the bone volume differed from that in the total porous space

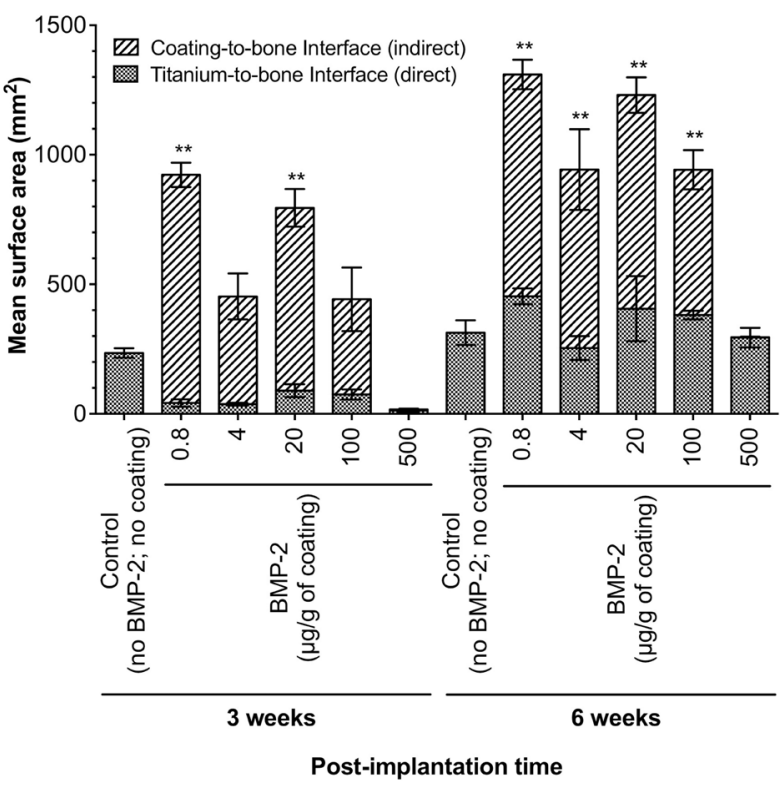

Fig. 10. Total area of the titanium surface that was covered either directly or indirectly (intervening layer of coating) with bone (BIC) 3 and 6 weeks after implant placement (mean values $\pm \mathrm{SEM} ; n=3$ in each case). The asterisks denote the level of statistical significance $(* * p<0.01)$ of comparisons of total (direct plus indirect) $\mathrm{BIC}$ with the control at each time point.

Surface area of bone in the porous space of the titanium mesh

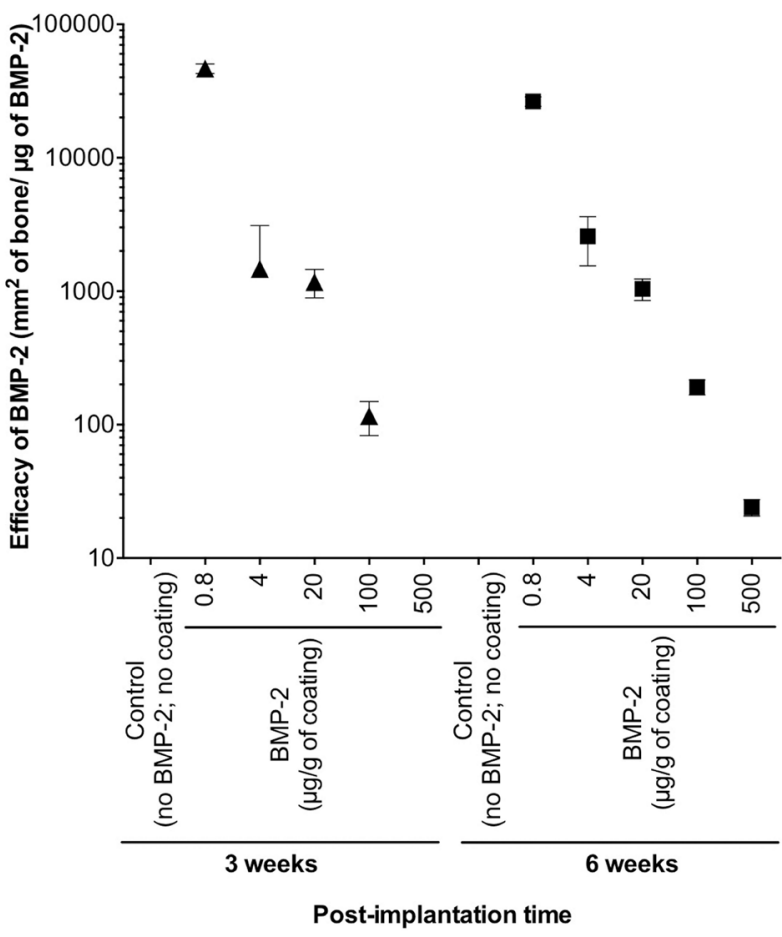

Fig. 11. Net efficacy of BMP-2 - as appertaining to the surface area of bone in the porous space of the titanium mesh -3 and 6 weeks after implant placement, represented on a decadal logarithmic scale. Negative values $(500 \mu \mathrm{g}$ of BMP-2/g of coating at 3 weeks $)$ cannot be depicted on this scale [mean values \pm SEM; $n=3$ in each case. Correlation coefficients $(\rho): \rho_{3 \mathrm{w}}=-0.76 ; \rho$ $\left.{ }_{6 \mathrm{w}}=-0.38\right]$. 
Table 5. Net efficacy of BMP-2: Dose-dependency as appertaining to the surface area of bone in the porous space of the titanium mesh, 3 and 6 weeks after implant placement. Mean values $\pm \mathrm{SEM} ; n=3$ in each case.

\begin{tabular}{|c|c|c|}
\hline \multirow{2}{*}{$\begin{array}{c}\text { BMP-2-concentration group } \\
(\boldsymbol{\mu g} / \mathbf{g} \text { of coating) }\end{array}$} & \multicolumn{2}{|c|}{ Surface area of bone $\left(\mathbf{m m}^{2} / \boldsymbol{\mu g}\right.$ of BMP-2) } \\
\cline { 2 - 3 } $\mathbf{3}$ weeks & 6 weeks \\
\hline 0.8 & $46639.5 \pm 3823.2$ & $26433.5 \pm 2154.3$ \\
\hline 4 & $1468.6 \pm 1,639.3$ & $2582.0 \pm 1034.3$ \\
\hline 20 & $1172.2 \pm 281.4$ & $1042.1 \pm 190.8$ \\
\hline 100 & $116.0 \pm 33.2$ & $191.5 \pm 24.5$ \\
\hline 500 & $-17.2 \pm 4.5$ & $24.0 \pm 3.4$ \\
\hline
\end{tabular}

A

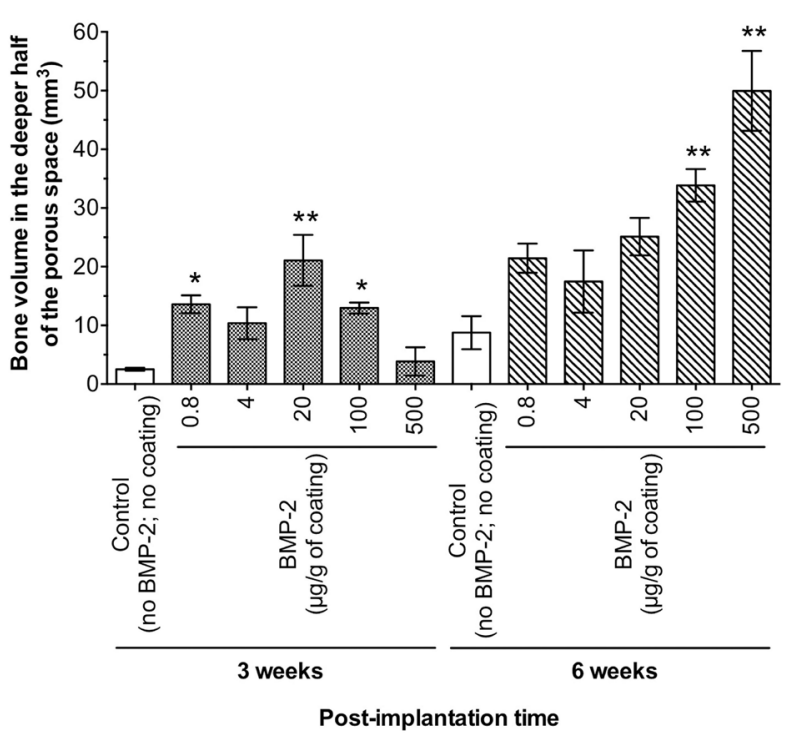

B

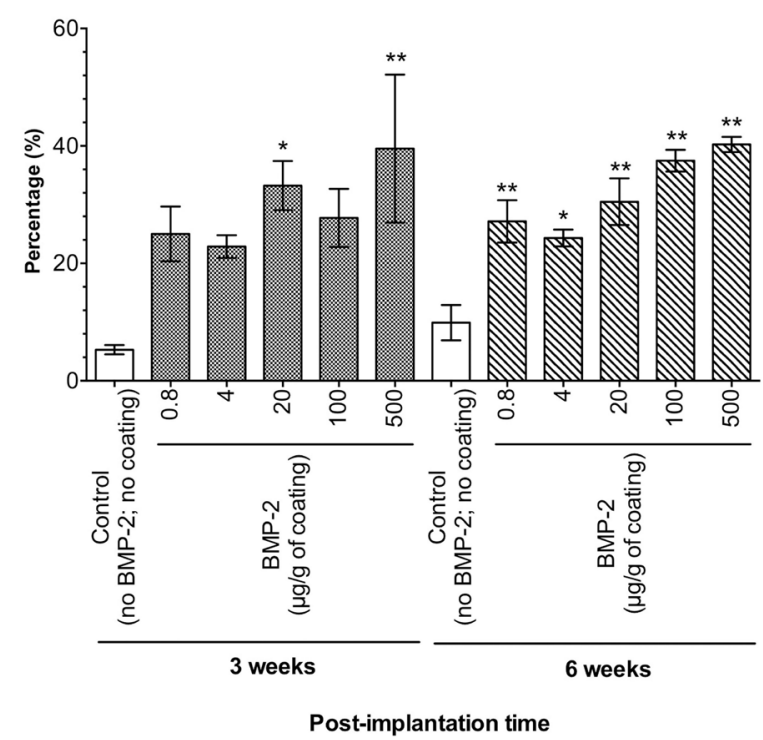

Fig. 12. Volumes of neo-formed bone in the deeper half of the porous space of the titanium mesh. (A) Absolute volumes of neo-formed bone in the deeper half of the porous space of the titanium mesh 3 and 6 weeks after implant placement (mean values $\pm \mathrm{SEM} ; n=3$ in each case). The asterisks denote the levels of statistical significance $\left({ }^{*} p<0.05\right.$; ** $p<0.01$ ) of comparisons with the control at each time point. (B) Volume of bone in the deeper half of the porous space of the titanium mesh, expressed as a fraction (percentage) of that in the total porous space [deeper (inner) and outer halves], 3 and 6 weeks after implant placement (mean \pm SEM; $n=3$ in each case). The asterisks denote the levels of statistical significance $(* p<0.05 ; * * p<0.01)$ of comparisons with the control at each time point.

(Fig. 12A and Fig. 6A). The deposition of bone in the deeper half tended to be higher than in the controls at all BMP2 concentrations and at both time points. At the 3-week juncture, the differences attained statistical significance at BMP-2 concentrations of $0.8 \mu \mathrm{g} / \mathrm{g}$ of coating $(p=0.028)$, $20 \mu \mathrm{g} / \mathrm{g}$ of coating $(p=0.001)$ and $100 \mu \mathrm{g} / \mathrm{g}$ of coating $(p=0.039)$. At the 6-week juncture, statistical significance was achieved at BMP-2 concentrations of $100 \mu \mathrm{g} / \mathrm{g}$ of coating $(p=0.005)$ and $500 \mu \mathrm{g} / \mathrm{g}$ of coating $(p<0.001)$.

Bone-volume fractions in the deeper half of the porous space likewise tended to be higher than in the controls at all BMP-2-concentrations and at both time points (Fig. 12B). However, at the 3-week juncture, the differences attained statistical significance only at BMP-2 concentrations of $20 \mu \mathrm{g} / \mathrm{g}$ of coating $(p=0.03)$ and $500 \mu \mathrm{g} / \mathrm{g}$ of coating $(p=0.008)$. At the 6 -week juncture, on the other hand, the differences were statistically significant at all BMP-2 concentrations.

The proportion of the deeper half of the porous space that was filled with neo-formed bone in the controls was
$5.3 \pm 0.8 \%$ and $9.9 \pm 3.0 \%$ at the 3 - and 6 -week junctures, respectively. In the experimental groups, the values at the 3 -week juncture ranged from $22.9 \pm 1.9 \%(4 \mu \mathrm{g}$ of BMP$2 / \mathrm{g}$ of coating) to $39.5 \pm 12.6 \%(500 \mu \mathrm{g}$ of BMP- $2 / \mathrm{g}$ of coating); those at the 6 -week one from $24.3 \pm 1.4 \%(4 \mu \mathrm{g}$ of BMP-2/g of coating) to $40.3 \pm 1.3 \%(500 \mu \mathrm{g}$ of BMP2/g of coating) (Fig. 12B).

The use of BMP-2 was expected to be associated with an increase in the depth to which bone penetrated the porous space of the titanium mesh and thereby to have a positive influence on the osseointegration of the implant and the strength of its mechanical fixation. The findings for the net in-growth pattern and penetration depth of the neo-formed bone (values normalised to those in the controls) (Table 6) accord with these expectations.

\section{Net BMP-2 efficacies as appertaining to neo-formed bone volume}

As appertaining to the volume of neo-formed bone in the porous space of the titanium mesh, the net efficacy 
Table 6. Net volumes of bone in the deeper half of the porous space of the titanium mesh 3 and 6 weeks after implant placement, and the fold-increase in this parameter between the BMP-2-concentration groups. Mean values \pm SEM; $n=3$ in each case.

\begin{tabular}{|c|c|c|c|}
\hline \multirow{2}{*}{$\begin{array}{c}\text { BMP-2-concentration group } \\
(\boldsymbol{\mu} \mathbf{g} / \mathbf{g} \text { of coating) }\end{array}$} & \multicolumn{3}{|c|}{ Net bone volume $\left(\mathbf{m m}^{\mathbf{3}}\right)$} \\
\cline { 2 - 4 } & $\mathbf{3}$ weeks & & 6 weeks \\
\hline $\mathbf{0}$ (control) & $\mathbf{0}$ & Fold-increase & $\mathbf{0}$ \\
\hline 0.8 & $11.1 \pm 1.5$ & $\times 11$ & $12.7 \pm 2.5$ \\
\hline 4 & $7.8 \pm 2.7$ & $\times 8$ & $8.7 \pm 5.3$ \\
\hline 20 & $18.6 \pm 4.3$ & $\times 18$ & $16.4 \pm 3.2$ \\
\hline 100 & $10.4 \pm 0.9$ & $\times 10$ & $25.1 \pm 2.8$ \\
\hline 500 & $1.3 \pm 2.4$ & $\times 1$ & $41.2 \pm 6.8$ \\
\hline
\end{tabular}

A Bone volume in the total porous space of the titanium mesh

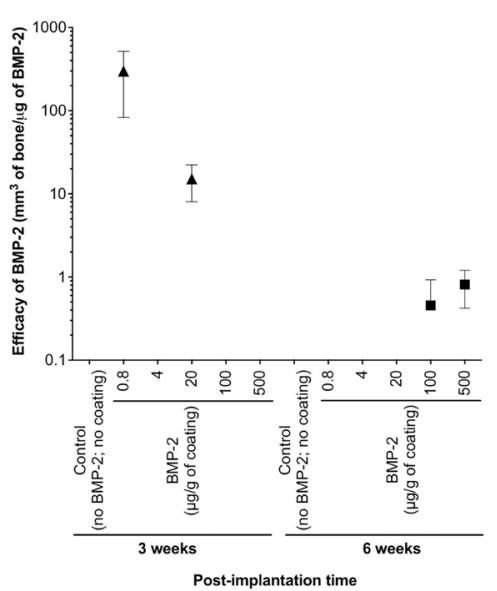

B

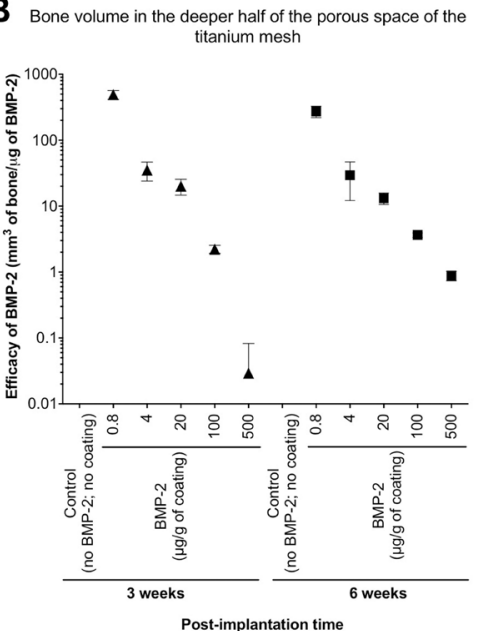

C Neo-formed bone volume in the peri-implant space

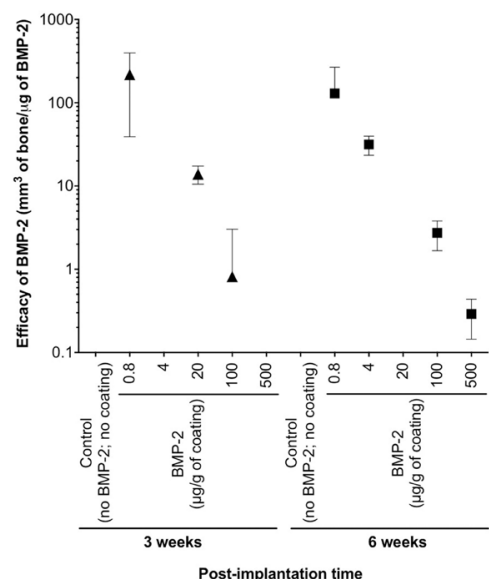

Fig. 13. Efficacies of BMP-2. (A) Net efficacy of BMP-2 - as appertaining to the volume of bone in the total porous space of the titanium mesh -3 and 6 weeks after implant placement, represented on a decadal logarithmic scale [mean values \pm SEM; $n=3$ in each case. Correlation coefficients $\left.(\rho): \rho_{3 \mathrm{w}}=-0.31 ; \rho_{6 \mathrm{w}}=0.46\right]$. (B) Net efficacy of BMP-2 - as appertaining to the volume of bone in the deeper half of the porous space of the titanium mesh -3 and 6 weeks after implant placement, represented on a decadal logarithmic scale [mean values \pm SEM; $n=3$ in each case. Correlation coefficients $(\rho): \rho_{3 \mathrm{w}}=-0.37 ; \rho_{6 \mathrm{w}}=-0.39$ ]. (C) Net efficacy of BMP-2 - as appertaining to the volume of neo-formed bone in the peri-implant space -3 and 6 weeks after implant placement, represented on a decadal logarithmic scale [mean values \pm SEM; $n=3$ in each case. Correlation coefficients $(\rho)$ : $\rho_{3 \mathrm{w}}=-0.37 ; \rho_{6 \mathrm{w}}=-0.53$ ].

of BMP-2 was not linearly related to the concentration of the agent and the intra-group variation was fairly high (Fig. 13A) $\left(\rho_{3 \mathrm{w}}=-0.31 ; \rho_{6 \mathrm{w}}=0.46\right)$. With respect to the net volumes of neo-formed bone in the deeper half of the porous space of the titanium mesh, the net BMP-2 efficacy decreased with an increase in BMP-2 concentration at both time points (Fig. 13B), although the relationship was not linear $\left(\rho_{3 \mathrm{w} 3 \mathrm{w}}=-0.37 ; \rho_{6 \mathrm{w} 3 \mathrm{w}}=-0.39\right)$. However, if the data appertaining to the lowest and the highest BMP-2 concentrations were excluded, good correlations between the values at dosages of 4 and $100 \mu \mathrm{g} / \mathrm{g}$ of coating were disclosed $\left(\rho_{3 \mathrm{w} 3 \mathrm{w}}=-0.95 ; \rho_{6 \mathrm{w} 3 \mathrm{w}}=-0.87\right)$. A similar picture was revealed for the net bone surface area, with but one anomaly ( $4 \mu \mathrm{g} / \mathrm{g}$ of coating at the 3 -week juncture) (Fig. 11). The BMP-2 efficacy for the neo-formed bone volume in the peri-implant space likewise decreased with an increase in BMP-2 concentration $\left(\rho_{3 \mathrm{w} 3 \mathrm{w}}=-0.37\right.$; $\left.\rho_{6 \mathrm{w} 3 \mathrm{w}}=-0.53\right)($ Fig. 13C).

\section{Discussion}

To affect a mechanically stable and durable osseointegration of orthopaedic and dental implants, and thereby to guarantee their longevity without loosening, is an important therapeutic goal in clinical practice. The process can be facilitated by functionalising the surfaces of titanium prostheses with a calcium-phosphate (bone-matrix-like) layer into which the osteoinductive agent BMP-2 has been incorporated (Boyne and Jones, 2004; Liu et al., 2006). By virtue of this mode of delivery, BMP-2 is released gradually and steadily at a low-dose rate during the coating's osteoclast-mediated degradation - not spontaneously and rapidly in a single high-dose burst (Bhakta et al., 2013) - whereby the sustained local formation of bone is promoted (Liu et al., 2005a; Liu et al., 2007). However, BMP-2 is known to induce not only the formation, but also the resorption of bone, and at high concentrations, the equilibrium between the two processes is tipped very much in favour of the latter (Nakamura et al., 2009; 
Nakamura et al., 2003). No investigation has as yet been undertaken in vivo to determine the dosage window within which osteoinduction is maximised and bone resorption minimalised. The aim of the present study was to clarify this issue, to which end, porous titanium implants bearing different calcium-phosphate-coating-incorporated dosages of BMP-2 were inserted into the tibial bone of adult sheep. Various stereological estimators that are of relevance to the issue at stake were histomorphometrically evaluated 3 and 6 weeks after surgery.

\section{Coating degradation and BMP-2 release}

The degree to which the implant coating had been degraded by the 3 rd postoperative week (Fig. 4), which governed the amount of BMP-2 that was released (Fig. 5A), increased in parallel with the concentration of the osteoinductive agent. The dose-dependent increase in the rate of coating degradation (Fig. 5B) can be accounted for by the likewise dose-dependent induction of osteoclast formation and a concomitant augmentation of osteoclast-mediated coating degradation activity. By the 6th postoperative week, the situation had stabilised (Fig. 4), insofar as the total amount of degraded coating was somewhat lower than at the 3-week juncture. This finding implies that the daily rate of coating degradation was lower at the later than at the earlier time point. To account for this observation, we need to look no further than at the healing of a fractured or a lesioned bone in nature. This process involves a sequence of temporally defined events, which begins with the osteolysis of fragments of pre-existing bone (analogous to the osteoclast-mediated degradation of the coating during the first 3 postoperative weeks) (LissenbergThunnissen et al.,2011; Noda et al., 2009; Schell et al., 2006). Later (after 3 weeks), bone-formative activity outweighs osteolytic activity (analogous to the slower rate of osteoclast-mediated coating degradation between the $3 \mathrm{rd}$ and the 6th postoperative weeks). The natural osteolytic process, as well as the rate of coating degradation, will be influenced by the local availability of BMP-2, which will be governed by the agent's osteoclast-mediated liberation from a likewise local source - the indigenous bone matrix or the coating - during the material's osteoclast-mediated degradation and potentiated at high local concentrations of the agent. At the highest BMP-2 concentration, no coating remained at the 6-week juncture (Fig. 4), a finding that is indicative of a BMP-2-overdose situation. At all other BMP-2 concentrations ( 0.8 to $100 \mu \mathrm{g} / \mathrm{g}$ of coating), residual coating material remained at this later time point. BMP-2 is trapped within this residual coating material and serves as a reserve for the continued stimulation of bone formation activity and the long-term consolidation of osseointegration. If the coating has undergone complete degradation by the 6th postoperative week, then the depot of BMP-2 will have been exhausted and the process of osseointegration arrested.

When BMP-2 is available in a free form, which is the case if it is adsorbed onto the surface of a titanium implant, then it is liberated rapidly in a single high-dose burst, which promotes osteolysis (Nakamura et al., 2009; Nakamura et al., 2003). In clinical practice, this mode of BMP-2 delivery was hitherto (McClellan et al., 2006; Saigal et al.,
2012; Singh et al., 2013), and still is, the norm (Faundez et al., 2016). A coating of calcium phosphate is in itself osteoconductive (Liu et al., 2007; Wong et al., 1995), but not osteoinductive (Liu et al., 2007). This attribute can be conferred only by an osteogenic agent, such as BMP-2. A calcium-phosphate coating into which BMP-2 has been biomimetically incorporated thus serves a dual function: it acts as an osteoconductive layer and as a vehicle for the slow, sustained delivery of the osteoinductive agent at low doses (Figs. 5A, B).

\section{Bone volumes}

Within the range of BMP-2 concentrations ( 0.8 to $500 \mu \mathrm{g} / \mathrm{g}$ of coating) that was tested in our model, the net volume of neo-formed bone did not differ significantly from that in the control, either in the porous space of the titanium mesh or in the peri-implant space, and at neither the 3-nor the 6-week juncture, with but one anomaly (Figs. 6A, B). At the highest concentration of BMP-2 $(500 \mu \mathrm{g} / \mathrm{g}$ of coating $)$, the net volume of neo-formed bone in the porous space was considerably lower than that in the other experimental groups and in the control at the 3-week juncture, whereas at the 6 -week one, the value was the highest of all. This pattern of osteogenesis points to a gross imbalance between bone formation and resorption, with the latter greatly outweighing the former at the earlier time point - a phenomenon that reflects the high rate of release of BMP-2 from the coating during the initial postoperative phase, as explained in the previous section. In clinical practice, a situation such as this is to be avoided, especially in patients suffering from osteoporosis, since the risk of implant dislocation, early loosening and even pathological fracturing would be greatly heightened. Likewise at the highest concentration of BMP-2 $(500 \mu \mathrm{g} / \mathrm{g}$ of coating), the net volume of total bone (pre-existing and neo-formed) in the peri-implant space did not differ significantly from that in the control at either of the two time points (Fig. 6B).

\section{Bone surface areas and $\mathrm{BIC}$}

BMP-2 enhanced the total surface area of bone in the porous space of the titanium mesh relative to that in the control at all concentrations and at both time points, with but one anomaly (Fig. 8A). At the highest BMP-2 concentration $(500 \mu \mathrm{g} / \mathrm{g}$ of coating), the total surface area of bone in the porous space - like the net volume - was significantly lower than that in the control at the 3-week juncture. But in contrast to the finding for net bone volume, the value for total bone surface area at the 6-week juncture was not higher than, but comparable to, those at the other BMP-2 concentrations. An explanation for the anomalous results at the highest dosage of BMP-2 is furnished under "Coating degradation and BMP-2 release".

In the porous space, the increase in the total surface area of bone relative to that in the control at the 3 -week juncture attained statistical significance at BMP-2 concentrations of 0.8 and $20 \mu \mathrm{g} / \mathrm{g}$ of coating (Fig. 8A). At the 6-week juncture, the increases relative to the control value were statistically significant at all BMP-2 concentrations except at $4 \mu \mathrm{g} / \mathrm{g}$ of coating. A detailed inspection of the data for the individual implants in the latter case revealed the existence of outliers in the estimations of bone volume 
and bone surface area. This circumstance is reflected in the high standard errors of the mean (Fig. 6A and Fig. 8A, respectively). The high coefficients of variation, combined with the low $n$-value $(=3)$, can readily lead to statistical non-significance in a comparison of data between groups.

That the surface area but not the volume of neo-formed bone increased in the porous space reflects the presence of the osteoconductive and osteoinductive coating. An inspection of the histological images revealed neo-formed bone to be preferentially deposited along the surface of the coating-lined pores, not within the "empty" porous space itself (Figs 2A, B). Hence, the presence of the BMP-2-functionalised coating changed the pattern of bone formation in the porous space of the titanium mesh relative to that in the control. This change led to an increase in the (indirect) BIC (Fig. 10), which would have optimised the osseointegration of the implant. Although the highest BIC-values were attained at BMP-2 concentrations of 0.8 and $20 \mu \mathrm{g} / \mathrm{g}$ of coating at both time points, increases in this parameter were achieved at all dosages below $500 \mu \mathrm{g} / \mathrm{g}$ of coating, viz., between 0.8 and $100 \mu \mathrm{g} / \mathrm{g}$ of coating.

In the peri-implant space, the total surface area of neoformed and pre-existing bone did not differ markedly from that in the control at the end of the 6-week monitoring period (Fig. 8B). Only during the first 3 weeks did the surface area of neo-formed bone increase relative to that in the control, but even then only at BMP-2 concentrations of between 0.8 and $20 \mu \mathrm{g} / \mathrm{g}$ of coating (Fig. 8B). From the end-point results, it can be inferred that the domain of influence of BMP-2 was confined to the porous space of the titanium mesh during the $3 \mathrm{rd}$ to the 6 th postoperative weeks at low dosages of the agent. The daily rate of release of BMP-2 was higher during the initial 3 weeks than during the 3 rd to the 6 th weeks (Fig. 5A, B), and the higher local levels of the agent that were thereby generated during this early phase relative to those that were produced during the latter one, probably influenced the pattern of neo-bone formation along the coating-lined surface of the pores.

Given that the surface area of neo-formed bone in the porous space increased without a concomitant increase in its volume, the mean thickness of the trabeculae therein decreased significantly relative to that in the control at all BMP-2 concentrations and at both time points, with but one anomaly ( $500 \mu \mathrm{g} / \mathrm{g}$ of coating at the 6 -week juncture) (Fig. 9). In the peri-implant space, the mean thickness of the trabeculae of neo-formed bone did not differ significantly from that in the control at any of the BMP-2 concentrations and at neither of the two time points. The mean thickness of the trabeculae of pre-existing bone tendentially decreased relative to that in the control during the first 3 weeks of monitoring at all BMP-2 concentrations, although the differences attained statistical significance only at 4 and $500 \mu \mathrm{g} / \mathrm{g}$ of coating. During the $3 \mathrm{rd}$ to the 6 th weeks, the mean thickness of the trabeculae of pre-existing bone did not differ significantly from that in the control at any of the BMP-2 concentrations. At the highest BMP-2 concentration ( $500 \mu \mathrm{g} / \mathrm{g}$ of coating), the mean thickness of the trabeculae of pre-existing bone during the initial resorption phase was not compensated for by the deposition of neo-formed bone during the later one. Hence, by the end of the 6th week, the mean value for this parameter was tendentially lower at the highest than at the lower dosages of the agent (Figs 9B, C).

\section{BMP-2 Efficacy}

As appertaining to the total volume of neo-formed bone in the porous space of the titanium mesh, no clear dosedependent trend was identifiable on a linear scale. Albeit so, at the highest concentration of the agent $(500 \mu \mathrm{g} / \mathrm{g}$ of coating), the BMP-2 efficacy tended towards zero.

As aforementioned, BMP-2 had a clear influence on the pattern of bone formation along the coating-lined surface of the pores in the titanium mesh. And this influence was also apparent in the net efficacy of the agent, which increased with a decrease in BMP-2 concentration (Fig. 11). If the data appertaining to the lowest dosage were excluded, then for each 5-fold-step increase in BMP-2 concentration, the net efficacy of the agent decreased with a reciprocation factor of almost 5.7-fold during the 6-week monitoring period. If the data appertaining to the lowest BMP-2 concentration were included, then the corresponding decrease in the efficacy of the agent was 9.5 -fold. These calculations reveal the efficacy of the lowest concentration of BMP-2 $(0.8 \mu \mathrm{g} / \mathrm{g}$ of coating) to greatly exceed that of the 5 -fold-higher one ( $4 \mu \mathrm{g} / \mathrm{g}$ of coating). We therefore surmise that the tipping point in the equilibrium between bone formation and bone resorption probably occurs at a BMP- 2 concentration of about $4 \mu \mathrm{g} / \mathrm{g}$ of coating. The critical BMP-2 concentration range within which bone resorption grossly outweighs bone formation lies between 100 and $500 \mu \mathrm{g} / \mathrm{g}$ of coating in the present study (and above: see Materials and Methods section under "BMP-2 concentrations").

\section{Conclusions}

The presence of a BMP-2-functionalised calciumphosphate coating clearly increased the penetration depth at which neo-formed bone was deposited in the porous space of the titanium mesh during the 6-week monitoring period. In the control, approximately $5 \%$ of the porous space was penetrated in the deeper half of the porous space during the first 3 postoperative weeks, which rose to $10 \%$ during the $3 \mathrm{rd}$ to the 6 th weeks. In the presence of a BMP-2-funtionalised coating, the corresponding values were, on average, $30 \%$ and $31 \%$, respectively. The mean increase of 20 to $25 \%$ in the bony in-growth depth and the higher BIC-values indicate that the osseointegration of the implants was enhanced in the presence of a BMP-2functionalised coating. As appertaining to the deposition of neo-formed bone in the deeper half of the porous space, the efficacy of BMP-2 was high at all concentrations of the agent between 0.8 and $100 \mu \mathrm{g} / \mathrm{g}$ of coating at both time points. Hence, bone resorption activity was lower in the deeper (inner) than in the outer half of the porous space.

An optimally balanced osseointegrative effect was observed to occur at a BMP-2 concentration of $100 \mu \mathrm{g} / \mathrm{g}$ of coating. The neo-formation of bone during the first 3 weeks was moderate but still higher than that in the control, and the process was sustained during the 3 rd to the 6 th weeks at a higher level than at lower concentrations of the agent. 
The mean gains in bone volume between the $3 \mathrm{rd}$ and the 6th weeks were $20.9 \mathrm{~mm}^{3}$ (at $100 \mu \mathrm{g} / \mathrm{g}$ of coating) and $6.3 \mathrm{~mm}^{3}$ (at $<100 \mu \mathrm{g} / \mathrm{g}$ of coating), respectively. These findings indicate that the titanium implants were optimally osseointegrated in this model at BMP-2 concentrations of between 20 and $100 \mu \mathrm{g} / \mathrm{g}$ of coating, with a maximisation of the effect at a dosage of $100 \mu \mathrm{g} / \mathrm{g}$ of coating.

The findings of the present study revealed also that low concentrations of BMP-2 $(\leq 100 \mu \mathrm{g} / \mathrm{g}$ of coating) exerted a positive influence on the bone surface area and the BIC, as well as on the structural pattern of bone formation. The BMP2-concentration window for maximum osseointegration was broad, lying between 20 and $100 \mu \mathrm{g} / \mathrm{g}$ of coating. This dosage range lies well below the concentrations of BMP2 that are contained within commercial products, such as Infuse Bone Grafts (Medtronic). In this latter device, the BMP-2 concentrations range between $1.05 \mathrm{mg} / \mathrm{ACS}$ $(1.25 \mathrm{~cm} \times 5 \mathrm{~cm})$ and $12 \mathrm{mg} / \mathrm{ACS}(7.5 \mathrm{~cm} \times 10 \mathrm{~cm})(w w w$. medtronic.com, www.infusebonegraft.com). The use of our BMP-2-functionalised calcium-phosphate coating in clinical practice - optimised dosage-wise in the light of the findings of the present study - would permit a tremendous reduction in the local concentration of the agent, which would improve the efficacy of bone formation, enhance implant osseointegration, reduce the risk of triggering untoward side effects and lessen the costs of surgery.

\section{Acknowledgement}

The authors gratefully acknowledge the expert technical assistance of Melissa Anderson.

\section{References}

Baddeley AJ, Gundersen HJ, Cruz-Orive LM (1986) Estimation of surface area from vertical sections. J Microsc 142: 259-276.

Baylink DJ, Finkelman RD, Mohan S (1993) Growth factors to stimulate bone formation. J Bone Miner Res 8 Suppl 2: 565-572.

Benglis D, Wang MY, Levi AD (2008) A comprehensive review of the safety profile of bone morphogenetic protein in spine surgery. Neurosurgery 62: ONS423-431; discussion ONS431.

Bhakta G, Lim ZX, Rai B, Lin T, Hui JH, Prestwich GD, van Wijnen AJ, Nurcombe V, Cool SM (2013) The influence of collagen and hyaluronan matrices on the delivery and bioactivity of bone morphogenetic protein-2 and ectopic bone formation. Acta Biomater 9: 9098-9106.

Boyne P, Jones SD (2004) Demonstration of the osseoinductive effect of bone morphogenetic protein within endosseous dental implants. Implant Dent 13: 180-184.

Burkus JK, Heim SE, Gornet MF, Zdeblick TA (2003) Is INFUSE bone graft superior to autograft bone? An integrated analysis of clinical trials using the LT-CAGE lumbar tapered fusion device. J Spinal Disord Tech 16: 113-122.

Cahill KS, McCormick PC, Levi AD (2015) A comprehensive assessment of the risk of bone morphogenetic protein use in spinal fusion surgery and postoperative cancer diagnosis. J Neurosurg Spine 23: 86-93.

Cruz-Orive LM, Weibel ER (1990) Recent stereological methods for cell biology: a brief survey. Am J Physiol 258: L148-156.

Faundez A, Tournier C, Garcia M, Aunoble S, Le Huec JC (2016) Bone morphogenetic protein use in spine surgery-complications and outcomes: a systematic review. Int Orthop 40:1309-1319.

Gundersen HJ, Bendtsen TF, Korbo L, Marcussen N, Moller A, Nielsen K, Nyengaard JR, Pakkenberg B, Sorensen FB, Vesterby A, West MJ (1988) Some new, simple and efficient stereological methods and their use in pathological research and diagnosis. APMIS 96: 379-394.

Gundersen HJ, Jensen EB (1987) The efficiency of systematic sampling in stereology and its prediction. $\mathrm{J}$ Microsc 147: 229-263.

Hägi TT, Wu G, Liu Y, Hunziker EB (2010) Cellmediated BMP-2 liberation promotes bone formation in a mechanically unstable implant environment. Bone 46: 1322-1327.

Herberg S, Susin C, Pelaez M, Howie RN, Moreno de Freitas R, Lee J, Cray JJ, Jr., Johnson MH, Elsalanty ME, Hamrick MW, Isales CM, Wikesjo UM, Hill WD (2014) Low dose bone morphogenetic protein-2/stromal cellderived factor-1 beta cotherapy induces bone regeneration in critical-size rat calvarial defects. Tissue Eng Part A 20: 1444-1453.

Hofstetter CP, Hofer AS, Levi AD (2016) Exploratory meta-analysis on dose-related efficacy and morbidity of bone morphogenetic protein in spinal arthrodesis surgery. J Neurosurg Spine 24: 457-475.

James AW, LaChaud G, Shen J, Asatrian G, Nguyen V, Zhang X, Ting K, Soo C (2016) A review of the clinical side effects of bone morphogenetic protein-2. Tissue Eng Part B Rev 22: 284-297.

Lissenberg-Thunnissen SN, de Gorter DJ, Sier CF, Schipper IB (2011) Use and efficacy of bone morphogenetic proteins in fracture healing. Int Orthop 35: 1271-1280.

Liu Y, de Groot K, Hunziker EB (2005a) BMP-2 liberated from biomimetic implant coatings induces and sustains direct ossification in an ectopic rat model. Bone 36: 745-757.

Liu Y, Enggist L, Kuffer AF, Buser D, Hunziker EB (2007) The influence of BMP-2 and its mode of delivery on the osteoconductivity of implant surfaces during the early phase of osseointegration. Biomaterials 28: 2677-2686.

Liu Y, Hunziker EB, Layrolle P, De Bruijn JD, De Groot $\mathrm{K}$ (2004) Bone morphogenetic protein 2 incorporated into biomimetic coatings retains its biological activity. Tissue Eng 10: 101-108.

Liu Y, Hunziker EB, Randall NX, de Groot K, Layrolle P (2003) Proteins incorporated into biomimetically prepared calcium phosphate coatings modulate their mechanical strength and dissolution rate. Biomaterials 24: 65-70.

Liu Y, Li JP, Hunziker EB, de Groot K (2006) Incorporation of growth factors into medical devices via biomimetic coatings. Philos Trans A Math Phys Eng Sci 364: 233-248. 
Liu YM, de Groot K, Hunziker EB (2005b) Cellmediated protein release from calcium-phosphate-coated titanium implants. J Control Release 101: 346-347.

Malham GM, Giles GG, Milne RL, Blecher CM, Brazenor GA (2015) Bone morphogenetic proteins in spinal surgery: what is the fusion rate and do they cause cancer? Spine (Phila Pa 1976) 40: 1737-1742.

McClellan JW, Mulconrey DS, Forbes RJ, Fullmer N (2006) Vertebral bone resorption after transforaminal lumbar interbody fusion with bone morphogenetic protein (rhBMP-2). J Spinal Disord Tech 19: 483-486.

Nakamura M, Nakamichi Y, Nakamura H, Udagawa N (2009) Osteoclastogenesis and bone resorption. Nihon Rinsho 67: 889-896.

Nakamura M, Udagawa N, Matsuura S, Mogi M, Nakamura H, Horiuchi H, Saito N, Hiraoka BY, Kobayashi Y, Takaoka K, Ozawa H, Miyazawa H, Takahashi N (2003) Osteoprotegerin regulates bone formation through a coupling mechanism with bone resorption. Endocrinology 144: 5441-5449.

Noda M, Nagao M, Hanyu R, Miyai K, Ezura Y (2009) Bone fracture and the healing mechanisms. Molecular bases of fracture healing. Clin Calcium 19: 634-640.

Pobloth AM, Duda GN, Giesecke MT, Dienelt A, Schwabe P (2015) High dose recombinant human bone morphogenetic protein-2 impacts histological and biomechanical properties of a cervical spine fusion segment: results from a sheep model. J Tissue Eng Regen Med. DOI:10.1002/term.2049.

Saigal G, Quencer R, Guest JD, Cristescu MM, Lebwohl N (2012) Vertebral body osteolysis following the use of bone morphogenetic protein in spinal surgery: a mimicker of infection. J Neuroradiol 39: 354-359.

Schell H, Lienau J, Epari DR, Seebeck P, Exner C, Muchow S, Bragulla H, Haas NP, Duda GN (2006) Osteoclastic activity begins early and increases over the course of bone healing. Bone 38: 547-554.

Singh K, Nandyala SV, Marquez-Lara A, Cha TD, Khan SN, Fineberg SJ, Pelton MA (2013) Clinical sequelae after rhBMP-2 use in a minimally invasive transforaminal lumbar interbody fusion. Spine J 13: 1118-1125.

Tannoury CA, An HS (2014) Complications with the use of bone morphogenetic protein 2 (BMP-2) in spine surgery. Spine J 14: 552-559.

Vavken J, Mameghani A, Vavken P, Schaeren S (2015) Complications and cancer rates in spine fusion with recombinant human bone morphogenetic protein-2 (rhBMP-2). Eur Spine J. DOI:10.1007/s00586-015-38709.

Wong M, Eulenberger J, Schenk R, Hunziker E (1995) Effect of surface topology on the osseointegration of implant materials in trabecular bone. J Biomed Mater Res 29: $1567-1575$.

Wozney JM, Rosen V, Celeste AJ, Mitsock LM, Whitters MJ, Kriz RW, Hewick RM, Wang EA (1988) Novel regulators of bone formation: molecular clones and activities. Science 242: 1528-1534.

\section{Discussion with Reviewer}

Christopher Evans: This study lacks of a control group of animals in which the titanium was coated with calcium phosphate lacking BMP-2.What is the authors' reason behind this choice?

Authors: The purpose of the study was to elucidate the optimal BMP-2-dosage range that was needed for osteoinduction and for the osseointegration of the titanium mesh in vivo. Its aim was not to ascertain whether a coating of calcium phosphate alone, as an osteoconductive layer, would yield sufficient or comparable results. Moreover, this very issue was the subject of a previous study (Liu Y et al., 2007), which revealed a coating of calcium phosphate to be highly osteoconductive - as evidenced by high BIC-values - but, as expected, not osteoinductive. In a subsequent investigation, only experimental dental implants that bore a coating-incorporated depot of BMP-2 underwent rapid osseointegration; those that bore a coating alone or no coating at all did not (Hunziker et al., 2012).

Christopher Evans: No mechanical testing - e.g. pull-out strength - has been performed on the implants.

Authors: No such experiments were undertaken since it was not the purpose of the study to test the mechanical strength of the osseointegrated implants. An analysis of this kind would have made sense only if the implant model had borne a resemblance in size and shape to the prosthesis that would be applied in human patients. Moreover, such a study would entail an inclusion of all the appropriate negative control groups, as well as the instrumentation of more discriminative time points.

Christopher Evans: Fig. 6 suggests that BMP-2 induces no new bone formation at any time point. Likewise, Fig. $8 \mathrm{~B}$ suggests that the amount of new bone found in the peri-implant space falls at 6 weeks.

Authors: Fig. 8B illustrates the surface area of bone in the peri-implant space - not the amount of bone. As the reviewer correctly points out, the surface area of bone was lower at 6 than at 3 weeks. But this circumstance does not imply that the bone volume was likewise lower at 6 weeks. The authors assume that the increase in the mean thickness of the trabecular bone at 6 weeks had a bearing on the decrease in the surface area of bone (Fig. 9B).

\section{Additional References}

Hunziker EB, Enggist L, Küffer A, Buser D, Liu Y (2012) Osseointegration: the slow delivery of BMP-2 enhances osteoinductivity. Bone 51: 98-106

Editor's note: The Scientific Editor responsible for this paper was Christopher Evans. 